\title{
Fire design method for bar-reinforced circular and elliptical concrete filled tubular columns
}

\author{
Ana Espinos ${ }^{a}$, Manuel L. Romero ${ }^{\mathrm{a}, *}$, Antonio Hospitaler ${ }^{\mathrm{a}}$ \\ ${ }^{a}$ Instituto de Ciencia y Tecnología del Hormigón (ICITECH), \\ Universitat Politècnica de València, Valencia, Spain \\ * Corresponding author.e-mail address: mromero@mes.upv.es
}

\begin{abstract}
A method for calculating the design axial buckling load in the fire situation of unreinforced axially loaded concrete filled circular hollow section columns was presented by the authors in a previous paper [1]. In the present paper, the method is extended to barreinforced columns of circular and elliptical cross-section, as a necessary continuation to complete the proposal. The method presented here is based on the guidelines of Clause 4.3.5.1 in Eurocode 4 Part 1.2 for the fire design of composite columns and is developed on the basis of the results of new parametric studies, with varying values of the outer diameter of the column, steel tube wall thickness, relative slenderness, percentage of reinforcement and fire exposure time. From the results of these parametric studies, appropriate expressions and tables for the different parts which integrate the design method are derived. The proposed method is valid for centrally loaded bar-reinforced circular and elliptical concrete filled tubular columns, with a maximum percentage of reinforcement of a 5\% and makes allowance for columns with a high slenderness, extending the current limits of Eurocode 4 Part 1.2.

Keywords: Fire resistance; Concrete filled tubular columns; Eurocode 4; Simple calculation model; Reinforcement; Elliptical hollow section
\end{abstract}




\section{NOTATION}

a Half larger outer dimension of an elliptical section

$b \quad$ Half smaller outer dimension of an elliptical section

$A_{i} \quad$ Cross-sectional area of the of the part $i$ of the composite section

$A_{m} / V \quad$ Section factor

CFCHS Concrete filled circular hollow section

CFEHS Concrete filled elliptical hollow section

CFT Concrete filled tube

Outer diameter of the circular section

$E_{a, \theta}$

Modulus of elasticity of structural steel at the temperature $\theta$

$E_{c, \theta}$

Tangent modulus of concrete at the temperature $\theta$

$E_{s, \theta}$

Modulus of elasticity of reinforcing steel at the temperature $\theta$

$(E I)_{f i, e f f}$

Effective flexural stiffness in the fire situation

EC4

Eurocode 4

EHS

Elliptical hollow section

$f_{c}$

Compressive cylinder strength of concrete

$f_{s}$

Yield strength of reinforcing steel

$f_{y}$

Yield strength of structural steel

Second moment of area of the part $i$ of the cross-section at the temperature $\theta$

$L \quad$ Length of the column

$\ell_{\theta} \quad$ Buckling length of the column in the fire situation

$N$

Applied axial load

NF

French National Annex to Eurocode 4 Part 1-2

$N_{f i, c r}$

Elastic critical load in the fire situation

$N_{f i, p l, R d}$

Design cross-sectional plastic resistance to axial compression in fire

Design axial buckling load of the column in the fire situation

Perimeter of the section

Standard fire exposure time

Wall thickness of the steel tube

$u_{s} \quad$ Concrete cover

$\alpha$

Imperfection factor for the buckling curves

$\bar{\lambda}$

Relative slenderness of the column at room temperature

$\bar{\lambda}_{\theta}$

Relative slenderness of the column in the fire situation

Relative error 
Espinos A, Romero ML, Hospitaler A. Fire design method for bar-reinforced circular and elliptical concrete filled tubular columns. Eng Struct. 2013;56:384-95. doi: 10.1016/j.engstruct.2013.05.026

$\begin{array}{ll}\varphi_{i, \theta} & \text { Reduction coefficient to make allowance for the effect of thermal stresses } \\ \theta_{i, e q} & \text { Equivalent temperature of the part } i \text { of the cross-section } \\ \chi & \text { Member slenderness reduction factor }\left(\chi=N_{f i, R d} / N_{f i, p l, R d}\right) \\ \rho & \text { Percentage of reinforcement }\end{array}$

\section{INTRODUCTION}

The interest in the use and development of simple methods for calculating the fire resistance of concrete filled tubular (CFT) columns is growing, due to the increased usage of this structural typology [2]. Nevertheless, only a limited number of methods are accessible to designers for evaluating the fire resistance of this type of composite columns, which are a result of the numerical and experimental investigations carried out by the main research groups working in this field (Han et al. [3][4], Kodur et al. [5][6][7], Park et al. [8][9]).

In Europe, a method is available in EN 1994-1-2 [10] for calculating the fire resistance of CFT columns. Clause 4.3.5.1 describes a simple calculation model for evaluating the design axial buckling load of composite columns in the fire situation based on the elastic buckling theory. A specific method for columns composed of unprotected concrete filled hollow sections can also be found in Annex $\mathrm{H}$ of the same code. Given the complexity of the specific method in Annex $\mathrm{H}$ and after being revealed that it produces unsafe results for slender columns [11] [12] [13], authors are more inclined to follow the general principles in Clause 4.3.5.1. The work by the CTICM group in France [12] [14] must be pointed out, which has led to the rules published in the French National Annex to EN 1994-1-2 [15].

The authors of this paper presented a proposal for evaluating the design axial buckling load in the fire situation of unprotected CFT columns of circular shape [1], based on the general rules in Clause 4.3.5.1 of EN 1994-1-2. This new proposal was supported by the results of an extensive parametric study carried out with the help of a validated numerical model [16][17]. The method developed by the authors improved the accuracy of the current 
methods in EN 1994-1-2 and extended its current field of application. Nevertheless, the calculation of columns with reinforcement was not covered by the previous method, reason why the parametric study is extended here to complete the design proposal.

Another aspect that is of the interest of the authors is to extend the new proposal to concrete filled elliptical hollow section (CFEHS) columns, as no method is available yet for the fire design of this type of composite sections.

Despite the room temperature behaviour of elliptical hollow section (EHS) columns being widely studied in the last few years [18], with some incursions on the effect of filling these sections with concrete [19][20][21][22], the performance of CFEHS columns in the fire situation has not yet been investigated. Some recent work on unfilled EHS columns subjected to fire can be found in the literature [23][24], but no experimental studies have been carried out so far on concrete filled EHS columns exposed to fire. The only work which can be found in the literature on CFEHS columns exposed to fire is that presented by the authors of this paper [25] and the recent work from Dai \& Lam [26], who studied numerically the effect of the sectional shape on the fire behaviour of axially loaded CFT stub columns. It is worth noting that no design method for the calculation of the fire resistance of CFEHS columns has been developed yet.

In this paper, an extensive parametric study is carried out by means of a previously validated numerical model [16][17], where different values of the percentage of reinforcement are considered $(2.5 \%$ and $5 \%)$. By means of the results of these parametric studies, the simple calculation model proposed in the previous paper [1] is extended here to bar-reinforced columns. Appropriate values of the flexural stiffness reduction coefficients and buckling curves as a function of the percentage of reinforcement are developed in this paper, as well as expressions for the equivalent temperatures of the components of the composite section at different standard fire periods. Using the results of previous numerical investigations on 
CFEHS columns exposed to fire [25] the method is extended to be valid also for the increasingly used elliptical shapes. With this addition, the proposed simple calculation model is applicable to CFT columns of circular and elliptical shape, filled with normal strength concrete and using a maximum percentage of reinforcement of a 5\%. A wide range of column slenderness are covered in this method, with buckling lengths at elevated temperature up to 10 $\mathrm{m}$, diameters from $139.7 \mathrm{~mm}$ to $508 \mathrm{~mm}$ (major axis dimension from $150 \mathrm{~mm}$ to $500 \mathrm{~mm}$ in the case of elliptical columns) and standard fire classes from R30 to R120.

\section{PROPOSED SIMPLE CALCULATION MODEL FOR UNREINFORCED CIRCULAR CFT COLUMNS}

A method was proposed in the previous paper [1] which permits to evaluate the design axial buckling load in the fire situation $\left(N_{f i, R d}\right)$ of unreinforced CFT columns of circular crosssection, based on the general rules in Clause 4.3.5.1 of Eurocode 4 Part 1.2 [10]. A brief description of this method is given next.

\subsection{Simplified cross-sectional temperature field}

The first part of the proposed approach consists of a simple method for evaluating the cross-sectional temperature field of a concrete filled circular hollow section (CFCHS) column. A single equivalent temperature for the whole concrete core and another one for the steel tube are proposed, so as to obtain the same fire resistance of the column as by using the real non-uniform temperature distribution. In this way, the designer can evaluate the design axial buckling load of the column by using a single strength and stiffness value for each component of the composite cross-section corresponding to its temperature. A detailed explanation of the procedure for obtaining the equivalent temperatures of the different components of the cross-section can be found in [1]. 
A selection chart was proposed (Table 1) to facilitate designers obtain the equivalent temperature of the concrete core $\left(\theta_{c, e q}\right)$ and the steel tube $\left(\theta_{a, e q}\right)$ for a particular fire period directly from the value of the section factor of the column. For intermediate values of the section factor, linear interpolation can be used. Note that the section factor of a circular CFT column is calculated as $4 / D\left(\mathrm{~m}^{-1}\right)$.

A regression equation for the equivalent temperature of the concrete core valid for any fire resistance period was also developed, which includes the effect of $A_{m} / V$ and $R$ :

$$
\theta_{c, e q}=-186.44+5.764 R-0.026 R^{2}+22.577 A_{m} / V-0.32\left(A_{m} / V\right)^{2}+0.14 R \cdot A_{m} / V
$$

For the steel tube, the following equation can be used for evaluating the equivalent temperature, in function of $A_{m} / V$ and $R$ :

$$
\theta_{a, e q}=342.1+10.77 R-0.044 R^{2}+3.922 A_{m} / V-0.025 R \cdot A_{m} / V
$$

These equations can be used as an alternative to the selection chart for obtaining the equivalent temperatures at the standard fire periods (i.e. R30, R60, R90 and R120).

\subsection{Flexural stiffness reduction coefficients}

The application of the general principles in Clause 4.3.5.1 of EN 1994-1-2 [10] to CFT columns requires the definition of a set of reduction coefficients $\left(\varphi_{i, \theta}\right)$ for the evaluation of the effective flexural stiffness of the composite column (equation 3), which were proposed in the previous paper [1] for unreinforced columns.

$$
(E I)_{f i, e f f}=\sum_{j}\left(\varphi_{a, \theta} E_{a, \theta} I_{a, \theta}\right)+\sum_{m}\left(\varphi_{c, \theta} E_{c, \theta} I_{c, \theta}\right)=\varphi_{a, \theta} E_{a}\left(\theta_{a, e q}\right) I_{a}+\varphi_{c, \theta} E_{c}\left(\theta_{c, e q}\right) I_{c}
$$

The value of the concrete flexural stiffness reduction coefficient is taken as $\varphi_{c, \theta}=0.8$ and is used in combination with the initial tangent stiffness. This value accounts for the effect of the differential thermal stresses produced by the unequal temperature field along the width of the concrete cross-section. 
Note that EN 1994-1-2 defines the concrete stiffness in fire design using the secant modulus for the peak of the stress-strain curve. The tangent modulus in origin is 1.5 times the secant modulus, therefore $\varphi_{c, \theta}=0.8 \times 1.5=1.2$ if the secant modulus is used.

For the reduction coefficient of the steel tube $\left(\varphi_{a, \theta}\right)$, two options were given.

\section{Design equation}

A design equation was proposed for evaluating the reduction coefficient of the steel tube, in the form of a product of three factors which represent the effect of the parameters $D / t$, $A_{m} / V$ and $\ell_{\theta} / D$. $\varphi_{a, \theta}=\varphi_{a, \theta 1}(D / t) \times\left(2.747-1.48 \cdot\left(A_{m} / V\right)^{0.08}\right) \times\left(0.0813+0.0133 \cdot\left(\ell_{\theta} / D\right)^{1.097}\right) \leq 1$

In this equation, the reduction coefficient $\varphi_{a, \theta}$ is a product of two partial reduction coefficients lower than unity, $\varphi_{a, \theta_{2}}$ and $\varphi_{a, \theta 3}$, which are corrected by the factor $\varphi_{a, \theta_{1}}$ as a function of $D / t$ only for stocky columns $\left(\ell_{\theta} / D \leq 12\right)$, using the values tabulated in Table 2 . For $\ell_{\theta} / D>12, \varphi_{a, \theta l}=1$. For $\ell_{\theta} / D \geq 46$, the total factor $\varphi_{a, \theta}$ can be taken as equal to unity, which means that the reduction coefficient for the steel tube can be neglected.

\section{$\underline{\text { Tabulated data }}$}

A more simplistic proposal was also developed, in the form of a selection table where the values of the reduction coefficient $\varphi_{a, \theta}$ can be obtained as a function of the section factor $A_{m} / V$ and the elevated temperature slenderness, measured as $\ell_{\theta} / D$. The values of the reduction coefficient for the steel tube for different combinations of the two parameters can be found in Table 3. For intermediate values of $\ell_{\theta} / D$, linear interpolation may be used. To account for the effect of the cross-sectional slenderness of the steel tube, the resulting coefficient must be corrected by the factor $\varphi_{a, \theta l}$ as a function of $D / t$ if $\ell_{\theta} / D \leq 12$, using the values tabulated in Table 2. Again, for higher values of $\ell_{\theta} / D$, no correction is needed. 
Once the reduction coefficients for the steel tube and concrete core have been calculated through the proposed equations or tables, the general principles in Clause 4.3.5.1 of EN 19941-2 [10] can be followed for obtaining the design axial buckling load in the fire situation $\left(N_{f i, R d}\right)$, with the only particularity of using buckling curve "a" instead of "c".

\section{DEVELOPMENT OF A NEW SIMPLE CALCULATION MODEL FOR BAR- REINFORCED CIRCULAR CFT COLUMNS}

\subsection{Parametric studies}

A three-dimensional numerical model was developed by the authors by means of the finite element analysis package ABAQUS [27]. The main characteristics of the model were described in the previous paper [1]. This model is capable to simulate with enough accuracy the fire behaviour of slender concrete filled circular hollow section columns through a sequentially coupled thermal-stress analysis and has been validated against tests from the literature as well as against fire tests carried out by the own authors. Further details of the model and its validation process can be found in [16][17] and [28].

Parametric studies were performed by means of this numerical model. The main parameters affecting the buckling resistance of bar-reinforced CFT columns at elevated temperatures were investigated through these parametric studies. The parameters studied were the outer diameter of the column $(D)$, thickness of the steel tube wall $(t)$, relative slenderness of the column at room temperature $(\bar{\lambda})$ and standard fire period $(R)$. Additionally, two different values of the percentage of reinforcement $(\rho)$ were used: $2.5 \%$ and $5 \%$, with a constant value of the concrete cover $u_{\mathrm{s}}=30 \mathrm{~mm}$. This choice places on the safe side, since higher values of the concrete cover have a favourable effect on the fire behaviour of the columns [14]. The percentage of reinforcement (or reinforcement ratio) is defined as $\rho=$ $A_{s} /\left(A_{c}+A_{s}\right)$, with As the total cross-sectional area of the reinforcing bars and $A_{c}$ the cross- 
sectional area of concrete, excluding the space taken by the reinforcing bars. The concrete cover $u_{\mathrm{s}}$ is measured as the minimum distance between the axis of the longitudinal reinforcements and the internal surface of the steel tube.

For the concrete infill, a compressive strength of $30 \mathrm{MPa}$ was assumed. For the structural steel, a yield strength of $355 \mathrm{MPa}$ was used, while for the reinforcing steel, a yield strength equal to $500 \mathrm{MPa}$ was considered.

Six different circular section sizes of commercially available dimensions were employed: 139.7, 193.7, 273, 323.9, 406.4 and $508 \mathrm{~mm}$. For each diameter, two steel tube wall thicknesses were selected. For each cross-section, different column lengths were used, corresponding to different slenderness values at room temperature. All the columns were simulated as pinned-pinned and exposed uniformly to the ISO-834 standard fire curve in all their length. The relative slenderness of the columns at room temperature was calculated in accordance with Clause 6.7.3.3 of EN 1994-1-1 [29] assuming hinged end conditions. The influence of enhanced concrete confinement was not considered in the room temperature calculations. The maximum slenderness analysed for each cross-section was selected in such a way that the associated buckling length of the column did not exceed 10 meters, in order to reduce the computational cost of this study.

The combinations of diameters and member slenderness were as follows: $D=139.7 \mathrm{~mm}$ $(\bar{\lambda}=0.3,0.5,1,1.5,2) ; D=193.7 \mathrm{~mm}(\bar{\lambda}=0.3,0.5,1,1.5,2) ; D=273 \mathrm{~mm}(\bar{\lambda}=0.3,0.5,1$, 1.5); $D=323.9 \mathrm{~mm}(\bar{\lambda}=0.3,0.5,1) ; D=406.4 \mathrm{~mm}(\bar{\lambda}=0.3,0.5,1) ; 508 \mathrm{~mm}(\bar{\lambda}=0.3,0.5)$. For each column, four different standard fire resistance periods were considered: $30,60,90$ and 120 minutes, which are the common values prescribed in the design codes. In total, the number of cases analysed in this parametric study considering the two different reinforcement ratios was 352. A summary of the analysis cases is shown in Table 4. The process followed for obtaining the design axial buckling load of the columns at the different standard fire 
periods was as described in the previous paper [1]. The results obtained for all the column specimens analysed in these parametric studies can be accessed online [30].

From the results of this new series of simulations for bar-reinforced columns, the numerical buckling coefficient was computed. It was defined as the column axial buckling resistance obtained from the numerical simulation divided by the design value of the crosssectional plastic resistance, both in the fire situation: $\chi^{N U M}=\frac{N_{f i, R d}{ }^{N U M}}{N_{f i, p l, R d}}$. This value is plotted in Fig. 1 against the relative slenderness of the columns at elevated temperature $\bar{\lambda}_{\theta}=\sqrt{N_{f i, p l, R} / N_{f i, c r}}$, calculated as described in Clause 4.3.5.1 of Eurocode 4 Part 1.2 [10] and using reduction coefficients $\left(\varphi_{i, \theta}\right)$ equal to unity [31] for evaluating the effective flexural stiffness (equation 5).

$$
(E I)_{f i, e f f}=\varphi_{a, \theta} E_{a}\left(\theta_{a, e q}\right) I_{a}+\varphi_{c, \theta} E_{c}\left(\theta_{c, e q}\right) I_{c}+\varphi_{s, \theta} E_{s}\left(\theta_{s, e q}\right) I_{s}
$$

This was done for the two different values of the percentage of reinforcement. The results for unreinforced columns have been also included in Fig. 1, and buckling curve "c" has been superimposed for comparison purposes. Similar results to those obtained for unreinforced columns were found, with a similar trend in the three series of results, although it is important to note that lower values of the buckling coefficient are obtained as the reinforcement ratio increases. Therefore, for higher values of the percentage of reinforcement, the results are more deviated from the reference buckling curve and thus leading to more unsafe results. This suggests that the buckling curve should be revised for reinforced CFT columns, as a function of the percentage of reinforcement.

\subsection{Study and discussion of Eurocode 4 Part 1.2}

Based on the results of the parametric studies presented above, a comparison is done between the current calculation methods available in the Eurocode 4 Part 1.2 [10] for bar- 
reinforced CFT columns. Four different approaches are studied: Clause 4.3.5.1 with flexural stiffness reduction coefficients equal to unity (EC4(1)), Clause 4.3.5.1 with the reduction coefficients proposed by Aribert et al. [12] (EC4(2)), Annex H (EC4(H)), and French National Annex [15] (EC4(NF)).

Fig. 2 shows a comparison between the predictions and the numerical simulations in terms of normalised buckling load (divided by the theoretical cross-sectional plastic resistance).

Fig. 3 plots the relative error of the predictions $\xi$ against the relative slenderness of the columns at room temperature, for each of the design approaches studied. The relative error was computed as:

$$
\xi=1-\frac{N_{f i, R d}^{P R E D}-N_{f i, R d}^{N U M}}{N_{f i, R d}^{N U M}}
$$

with values greater than 1 meaning safe predictions and values lower than 1 meaning unsafe predictions.

As can be seen in Fig. 2a and Fig. 3a, EC4(1) yields unsafe results with a high dispersion of values for all the range of slenderness studied. Therefore, the flexural stiffness reduction coefficients cannot be neglected when applying Clause 4.3.5.1 to bar-reinforced CFT columns. Nevertheless, when the French coefficients are used in combination with Clause 4.3.5.1, Fig. 2b and Fig. 3b (EC4(2)), safe results are generally obtained, but with high errors and an elevated dispersion of results. As the slenderness is increased, the predictions become safer but the errors produced by this method are higher. Annex $\mathrm{H}$ predictions $(\mathrm{EC} 4(\mathrm{H}))$ turn from safe at low slenderness $(\bar{\lambda}=0.3)$ to unsafe for intermediate slenderness $(\bar{\lambda}=0.5-1.5)$ and close to the reference value again at $\bar{\lambda}=2$, Fig. $2 \mathrm{c}$ and Fig. $3 \mathrm{c}$. This effect was also observed for unreinforced columns, and confirms the findings from the CTICM group [12][14]. Note that in these two figures, those cases which are out of the applicability 
limits of Annex $\mathrm{H}\left(\ell_{\theta}>4.5 \mathrm{~m}\right)$ have been plotted with a hollow marker. Finally, EC4(NF) produces safe results for most of the cases analysed, but with a high error for slender columns Fig. 2d and Fig. 3d. Compared with the results obtained for unreinforced columns [1], it was observed that for bar-reinforced columns, all the methods produced a higher dispersion in the predictions and, in general, less conservative results were obtained.

\subsection{Simplified cross-sectional temperature field}

The temperature field of a CFT column with reinforcement is almost equal to that of an unreinforced column of the same cross-section. The presence of the reinforcing bars does not modify significantly the development of temperatures within the cross-section, therefore the equivalent temperatures of the steel tube and concrete core can be considered equal to the corresponding temperatures of the unreinforced columns, for which a proposal has been given.

In the case of the reinforcing bars, the equivalent temperatures corresponding to the different cross-sectional dimensions and standard fire periods can be obtained directly from the numerical results. Although only one value of the concrete cover was studied $\left(u_{s}=30\right.$ $\mathrm{mm}$ ), it is known that higher values of the concrete cover would reduce the temperature of the reinforcing bars, and therefore the proposed temperatures are on the safe side.

The evolution of the equivalent temperature of the reinforcing bars with the section factor of the columns is plotted in Fig. 4. As can be seen, as the fire exposure time increases, the equivalent temperature of the reinforcing bars becomes higher. An increase in the temperature was also found with the section factor. For each section factor and fire period, two points are plotted, corresponding to the two different steel tube wall thicknesses analysed for each cross-section. It can be observed that no significant influence is obtained with a change in the steel tube wall thickness, except for the lower fire period (R30), where higher 
temperatures were found for the sections with a lower steel tube wall thickness, since the reinforcing bars were located at a shorter distance from the exposed surface.

For each of the standard fire resistance classes studied, a regression curve was fitted to the data, as can be seen in Fig. 4. With the aid of the regression equations, a selection chart was built up (Table 5), which permits to obtain the equivalent temperature of the reinforcing bars for a particular fire period directly from the value of the section factor of the column. For intermediate values of the section factor, linear interpolation can be used.

An alternative equation for the equivalent temperature of the reinforcing bars was developed by using a multiple nonlinear regression analysis, including the effect of $A_{m} / V$ and $R$ and therefore valid for any fire resistance period:

$$
\theta_{s, e q}=-119.36+8.535 R-0.033 R^{2}+3.948 A_{m} / V+0.102 R \cdot A_{m} / V
$$

The temperature obtained through this equation can be used instead of that obtained by means of the selection chart.

\subsection{Flexural stiffness reduction coefficients}

Expressions and tables for obtaining the values of the flexural stiffness reduction coefficients for steel $\left(\varphi_{a, \theta}\right)$ and concrete $\left(\varphi_{c, \theta}\right)$ were proposed in [1] for unreinforced CFCHS columns, which must be used in combination with buckling curve "a" when applying the general rules in Clause 4.3.5.1 of EN 1994-1-2 [10]. For the concrete core, a constant reduction coefficient equal to 0.8 (with the initial tangent stiffness) was proposed, while for the steel tube a design equation was developed (equation 4), as function of the member slenderness (through $\left.\ell_{\theta} / D\right)$, cross-sectional slenderness $(D / t)$ and section factor $\left(A_{m} / V\right)$. Alternatively, Table 3 can be used for obtaining the reduction coefficient for the steel tube.

The validity of the proposed expressions for the flexural stiffness reduction coefficients of the steel tube and concrete core is studied here for the case of bar-reinforced columns, and 
the reduction coefficient corresponding to the reinforcing bars $\left(\varphi_{s, \theta}\right.$ in equation 5$)$ is derived. In addition, the more suitable buckling curves are studied for the case of bar-reinforced specimens.

It was found through the parametric studies that, as the reinforcement ratio increases, the normalised buckling load (or buckling coefficient) decreases, which gives as a result a higher deviation from the reference buckling curve, leading to unsafe results. Hence, it seems reasonable to modify the buckling curve for increasing reinforcement ratios. After a deep analysis of the numerical results for reinforced columns, buckling curve "b" was selected as the best fit to the data for a $2.5 \%$ reinforcement ratio, while buckling curve "c" was found the most suitable for the data corresponding to a $5 \%$ reinforcement ratio. Using the values of the flexural stiffness reduction coefficients for the steel tube $\left(\varphi_{a, \theta}\right)$ and concrete core $\left(\varphi_{c, \theta}\right)$ already proposed for unreinforced columns, the third coefficient corresponding to the reinforcing bars $\left(\varphi_{s, \theta}\right)$ was derived from statistical analysis. For a percentage of reinforcement equal to a $2.5 \%$, a constant value $\varphi_{s, \theta}=0.6$ was selected, while for a $5 \%$ reinforcement ratio $\varphi_{s, \theta}=0.3$ was obtained. No influence was observed of the rest of the parameters investigated (e.g. standard fire period, section factor, member slenderness, etc.) over the value of this reduction coefficient, so a constant value can be assumed for each reinforcement ratio. The proposed expressions for the reduction coefficients of the steel tube and concrete core, from the method for unreinforced columns, were found to be appropriate also for bar-reinforced columns, so they can be used as general values for CFT columns with any reinforcement ratio.

In order to summarize the results, the average and standard deviation values of the prediction errors of the proposals for the different reinforcement ratios studied is given in Table 6, where the values for unreinforced columns have also been included for comparison.

As can be seen, safer values are obtained by means of the design equation (4) than using the values in Table 3 for the evaluation of the reduction coefficient of the steel tube. This 
occurs for all the different reinforcement ratios studied. In any case, a good average value is obtained for all reinforcement ratios and under both approaches (design equation and tabulated data), although as the reinforcement ratio increases, the dispersion in the results also increase, which can be seen in the higher values of the standard deviation for $\rho=2.5 \%(0.14)$ and $\rho=5 \%(0.18)$ against 0.11 for unreinforced columns.

As an example of the results obtained with the proposal for reinforced columns, a comparison is shown in Fig. 5 between the predictions and the numerical simulations in terms of normalised buckling load, for columns with a $2.5 \%$ reinforcement ratio and using the values in Table 3 for the evaluation of the reduction coefficient of the steel tube. For the concrete core, $\varphi_{c, \theta}=0.8$ and for the reinforcing bars, a value $\varphi_{s, \theta}=0.6$ has been used. The buckling curve corresponding to this percentage of reinforcement has been used, i.e., buckling curve "b".

Fig. 6 presents the evolution of the buckling coefficient with the relative slenderness of the columns at elevated temperature, calculated with the proposed flexural stiffness reduction coefficients. It can be seen that the data follow closely the reference buckling curve ("b" in this case) in all the range of slenderness.

According to the results of this section, the buckling curves and values of the flexural stiffness reduction coefficient for the reinforcing bars summarized in Table 7 are proposed.

Although only two percentages of reinforcement have been studied (2.5\% and 5\%), for each range of values $(0 \%<\rho \leq 2.5 \%$ and $2.5 \%<\rho \leq 5 \%)$ the buckling curve and reduction coefficient corresponding to the upper limit $(2.5 \%$ or $5 \%)$ have been assigned, which places on the safe side. 


\subsection{Comparison with experiments and other methods}

The accuracy of the proposed method for bar-reinforced CFT columns is now compared with results of real fire tests. From the fire testing program carried out in Valencia by Romero et al. [28], three reinforced columns can be used (specimens RC159-6-3-30-0-20 to RC159-63-30-0-60), while other two bar-reinforced specimens can be found amongst the fire tests carried out at the NRCC [32], specimens C-48 and C-49.

Columns falling out of the applicability range of the method were left out of this comparative study (i.e. columns filled with high strength concrete or with sections other than circular). Fig. 7 compares the results of the tests against the predictions of the method, in terms of the failure load. It can be seen that the accuracy of the method was reasonable and, in general, safe predictions were obtained.

It is worth noting that, even though column C-48 - with a fire resistance time of 188 minutes - falls out of the applicability limits of the method $(R \leq 120 \mathrm{~min})$, a good estimation was also obtained for this specimen.

For comparing with the tests from Romero et al. [28], two options were considered: using the equivalent temperatures of steel and concrete given by the proposed method and using the real temperatures measured at the tests. As can be observed in Fig. 7, a better approximation was obviously obtained using the measured temperatures; in any case, using the equivalent temperatures safe results were obtained for all the specimens compared.

Fig. 8 compares the results of the proposed method with the values of the predictions obtained by means of the simplified design equation from Kodur [5] used in North America. As can be seen, the proposed method results in more accurate predictions than the formula from Kodur, with a narrower dispersion. It can be therefore concluded that, compared to the existing methods, the proposed simple calculation model provides a reasonable accuracy also for bar-reinforced columns. 


\section{EXTENSION OF THE PROPOSED METHOD TO ELLIPTICAL COLUMNS}

\subsection{Simplified cross-sectional temperature field}

For the study of the equivalent temperatures of the steel tube and concrete core in CFEHS columns, a series of commercially available elliptical geometries were studied. Six different geometries were used, selecting for steel tube wall thickness an intermediate value within the available range [33]: $150 \times 75 \times 5 \mathrm{~mm}, 200 \times 100 \times 8 \mathrm{~mm}, 250 \times 125 \times 10 \mathrm{~mm}$, $300 \times 150 \times 12.5 \mathrm{~mm}, 400 \times 200 \times 12.5 \mathrm{~mm}$ and $500 \times 250 \times 12.5 \mathrm{~mm}$. For each of the selected geometries, a heat transfer analysis was performed by means of the numerical model developed by the authors [16][17], and once the temperature field had been obtained for the six geometries, the procedure explained in [1] was applied to these sections, so as to obtain the equivalent temperatures of the steel tube and the concrete core corresponding to the standard fire periods (R30, R60, R90 and R120).

The trend in the evolution of the equivalent temperatures with the section factor and fire resistance period was similar to that obtained for the circular columns [1], although the section factor values for the elliptical columns (from 10 to $45 \mathrm{~m}^{-1}$ ) were comparatively higher

than those of the circular columns in (from 5 to $30 \mathrm{~m}^{-1}$ ). In effect, the circular shape is "thermally" more efficient than the elliptical shape, since it exposes a lower surface for a certain volume, and thus it results in more reduced section factor values.

For each of the standard fire resistance classes studied, a regression curve was fitted to the data. With the aid of the regression equations, a selection chart was built up (Table 8), which allows obtaining the equivalent temperature of the steel tube and concrete core for a particular fire period directly from the value of the section factor of the column. For intermediate values of the section factor, linear interpolation can be used. 
Alternative equations for the equivalent temperatures of the concrete core and steel tube were also developed by using multiple nonlinear regression analysis. These expressions include the effect of $A_{m} / V$ and $R$ and therefore are valid for any fire resistance period.

For the concrete core:

$\theta_{c, e q}=-395.503+9.304 R-0.035 R^{2}+33.698 A_{m} / V-0.425\left(A_{m} / V\right)^{2}+0.035 R \cdot A_{m} / V$

For the steel tube:

$\theta_{a, e q}=300.845+11.209 R-0.044 R^{2}+4.219 A_{m} / V-0.029 R \cdot A_{m} / V$

These equations can be used as an alternative to the selection chart in Table 8 .

For CFEHS columns with reinforcement, the temperatures corresponding to the reinforcing bars were obtained from the numerical simulations of the elliptical sections studied, for a concrete cover value equal to $30 \mathrm{~mm}$. The temperature of the reinforcing bars was taken as that of the concrete core at their same location, i.e., at a depth equal to $30 \mathrm{~mm}$ measured from the internal surface of the steel tube.

It was observed that, as the fire exposure time increases, the equivalent temperature of the reinforcing bars becomes higher. Also an increase in the temperature was found for increasing section factors. These results were similar to those obtained for the circular columns, although a faster increase in temperatures was observed for the elliptical shapes.

For each of the standard fire resistance classes studied, a regression curve was fitted to the data. From these regression equations, a selection chart was built up (Table 9), which allows obtaining the equivalent temperature of the reinforcing bars for a particular fire period directly from the value of the section factor of the column. For intermediate values of the section factor, linear interpolation can be used.

An alternative equation for the equivalent temperature of the reinforcing bars was developed by using a multiple nonlinear regression analysis, including the effect of $A_{m} / V$ and $R$ and therefore valid for any fire resistance period: 


$$
\theta_{s, e q}=-255.1+10.106 R-0.039 R^{2}+8.036 A_{m} / V+0.062 R \cdot A_{m} / V
$$

\subsection{Flexural stiffness reduction coefficients}

A set of flexural stiffness reduction coefficients $\varphi_{i, \theta}$ was given in Section 2.2 for unreinforced CFCHS columns, which must be used in combination with buckling curve "a" when applying the general calculation model in Clause 4.3.5.1 of EN 1994-1-2 [10].

In this section, the validity of the proposed expressions and tables for the flexural stiffness reduction coefficients is studied for the case of CFEHS columns.

The shape of an ellipse is characterized by its outside dimensions $2 a$ (major axis) and $2 b$ (minor axis), therefore equation (4) cannot be evaluated through a single diameter in this case. Instead, an equivalent diameter must be assigned. In the first term of equation (4) $(D / t)$, a value $D_{e q}=P / \pi$ was used (i.e. the diameter of that circle which has the same perimeter $P$ than the elliptical section), while in the third term $\left(\ell_{\theta} / D\right)$, several options were considered:

- Option 1: using the major axis dimension $(D=2 a)$

- Option 2: using the minor axis dimension $(D=2 b)$

- Option 3: using $D=P / \pi$.

The same three options were considered for entering to Table 3 with a value of $\ell_{\theta} / D$.

A set of numerical results was available for a series of CFEHS columns analysed in the parametric studies presented in [25]. These simulation results were used for studying the validity of the proposed method for elliptical columns. For this purpose, the values of the buckling resistance from the numerical simulations $\left(N_{f i, R d} d^{N U M}\right)$ were compared with those obtained by means of the application of the simple calculation model $\left(N_{f i, R d} P R E D\right)$. The error in the predictions was computed as defined in equation (6).

Table 10 summarises the average and standard deviation of the error in the evaluation of the design axial buckling load in the fire situation of the columns, obtained by means of the 
proposed method under each of the three options for calculating the reduction coefficient of the steel tube $\left(\varphi_{a, \theta}\right)$, and using either the design equation (4) or the values in Table 3.

According to the results in this table, option 2 seems to be the most appropriate when applying the proposed method to elliptical columns. With the use of the design equation, this option provides a better average error (closer to unity), while for the tabulated data, although the mean value is not so accurate, the dispersion results much lower than under the other options.

Therefore, it is suggested to use the minor axis dimension $(D=2 b)$ for evaluating the slenderness $\ell_{\theta} / D$ of an elliptical column loaded in axial compression. This assumption is reasonable, since under concentric axial load, an elliptical column is more likely to buckle about its weak axis. For eccentric loads, further studies would be needed.

Although the results obtained by the application of the proposed method for CFCHS columns to elliptical columns are reasonably accurate, they can be improved. A deeper study of the CFEHS columns analysed reveals that the section factor values of the elliptical columns result considerably higher than those of the circular columns, with all the analysed columns having values of $A_{m} / V>20$ [25], and therefore corresponding to the last column in Table 3 . This suggests that a column should be added to this table in order to cover higher section factor values which can be reached for CFEHS columns. A proposal is given in Table 11 for columns with higher section factor values, which extends the applicability of Table 3 and is valid for both circular and elliptical CFT columns.

Using the updated table, a better agreement between the predictions and simulation results for the elliptical columns is found, with an average error equal to 1.00 and a standard deviation of 0.15 (see Table 12).

Finally, a specific formulation was developed for CFEHS columns. Using the simulation results available for the series of CFEHS columns analysed in the parametric 
studies presented in [25], the reduction coefficient for the steel tube $\varphi_{a, \theta}$ was calculated, fixing $\varphi_{c, \theta}=0.8$ and employing the procedure explained in [1]. A multiple nonlinear regression analysis was conducted over the theoretical values of $\varphi_{a, \theta}$ for the elliptical columns, using the shape of the previously proposed equation (3), and the following coefficients were obtained:

$\varphi_{a, \theta}=\varphi_{a, \theta 1}\left(D_{e q} / t\right) \times\left(1.73-0.72 \cdot\left(A_{m} / V\right)^{0.047}\right) \times\left(0.118+0.0015 \cdot\left(\ell_{\theta} / 2 b\right)^{1.72}\right) \leq 1$

In this equation, the reduction coefficient $\varphi_{a, \theta}$ is a product of two partial reduction coefficients lower than unity, $\varphi_{a, \theta_{2}}$ and $\varphi_{a, \theta 3}$, which are corrected by the factor $\varphi_{a, \theta_{1}}$ as a function of $D_{e q} / t$ only for stocky columns $\left(\ell_{\theta} / 2 b \leq 12\right)$, using the values tabulated in Table 2 . For $\ell_{\theta} / 2 b>12$, the factor $\varphi_{a, \theta l}$ is equal to unity. The equivalent diameter for evaluating the first term in this equation is calculated as $D_{e q}=P / \pi$, with $P=$ the perimeter of the elliptical section.

Using the proposed equation (11), a mean value of the error equal to 1.04 (safe) was obtained, with a reduced dispersion (0.10 standard deviation). The average and standard deviation values obtained under the different approaches studied are summarised in Table 12, where it can be seen that this option produced more conservative predictions and a controlled dispersion of results, although the proposal for circular columns (design equation or tabulated data) can also be applied to elliptical columns with accurate results.

In Fig. 9, a comparison is shown between the predictions and the numerical simulations in terms of normalised buckling load, for the proposed equation (11), specific for elliptical columns.

Fig. 10 presents the evolution of the buckling coefficient with the relative slenderness at elevated temperature, using the proposed equation (11). It can be seen that the data follow closely the reference buckling curve "a", with an excellent agreement for the higher 
slenderness and a moderated dispersion for intermediate slenderness. For low slenderness values, buckling coefficients higher that unity are obtained in some cases, which are attributed to the confinement effect in stub columns, which was not accounted for in the development of the design equation.

In conclusion, the proposed method for circular columns can also be applied to elliptical columns, under the two options: design equation or tabulated method, using the updated Table 11 for the latter. If a higher precision is required, equation (11) specific for elliptical columns can be applied, even though equation (4) can be used for both circular and elliptical columns, producing accurate results.

Although the parametric results which have been used in this section are limited to unreinforced columns [25] and therefore a specific proposal for CFEHS columns with reinforcement cannot be developed based on them, it is the aim of the authors to carry out in the future further parametric studies in order to complete the proposed method for barreinforced CFEHS columns.

\subsection{Comparison of the proposed method with experiments}

The accuracy of the design proposal exposed above for elliptical columns is next verified against the results of a series of fire tests carried out recently by the authors on slender CFEHS columns [16]. From this experimental program, only specimens E220-11012-3-30-00-20 (unreinforced) and RE220-110-12-3-30-00-20 (bar-reinforced) are studied, corresponding to columns loaded under concentric axial load. For each case, the applied axial load from the test is compared with the predicted design axial buckling load at the time of failure, using the proposed method.

The equivalent temperatures of the steel tube, concrete core and reinforcing bars are evaluated under two approaches: 
- Option 1: Equations developed for CFCHS columns (eq. 1,2 and 7)

- Option 2: Equations developed for CFEHS columns (eq. 8, 9 and 10)

Also the realistic temperature field obtained from the experiments is used here for comparison, where the representative temperatures of the different layers in which the section is subdivided are interpolated from the measurements at the location of the thermocouples (option 3).

After obtaining the corresponding temperatures for the steel tube, concrete core and reinforcing bars, the simple calculation method described in the previous sections is applied for evaluating the design axial buckling load in the fire situation of the columns, using either equation (4) or (11) for the flexural stiffness reduction coefficient of the steel tube $\left(\varphi_{a, \theta}\right)$. For the case of the bar-reinforced specimen (RE220-110-12-3-30-00-20), the reduction coefficient of the reinforcing bars $\left(\varphi_{s, \theta}\right)$, and the corresponding buckling curve have been selected from Table 7. Table 13 summarises the results obtained under the three different options, for one of the columns studied.

As it can be seen in Table 13, the option which produced a better agreement with the test result is option 2, with an error equal to 1.20 (safe) using equation (4) and 1.25 using equation (11) for the reduction coefficients. The result obtained by means of using the equivalent temperature expression developed for circular columns produced a higher error, although comparable to that obtained with the real temperatures from the test and both options resulting in safe predictions. Similar results were obtained for column RE220-110-12-3-3000-20. A comparison with the test results can clearly be seen in Fig. 11 for the two column specimens studied, where equation (4) has been used for calculating the steel tube reduction coefficient.

From this figure, it can be concluded that the proposed method produces reasonable results for elliptical columns, using either the equivalent temperature equations for circular or elliptical columns, although with more precision when the specific expressions for elliptical 
columns are used. Similar results are obtained using the real temperature field from the tests, which confirms that the method is valid for its application to elliptical columns.

\section{OVERVIEW OF THE PROPOSED CALCULATION METHOD}

A method has been presented for the calculation of the design axial buckling load in the fire situation $\left(N_{f i, R d}\right)$ of unreinforced and bar-reinforced concrete filled tubular columns of circular and elliptical shape. The proposed method follows the guidelines in Clause 4.3.5.1 of EN 1994-1-2 [10], using specific expressions for evaluating the temperatures of the different components of the composite section, as well as their flexural stiffness reduction coefficients and the suitable buckling curve for the different reinforcing ratios. An overview of the proposed method is given in Table 14 .

The applicability limits of the proposed calculation method are the following:

- Buckling length in the fire situation: $\ell_{\theta} / D<50$ and $\ell_{\theta}<10 \mathrm{~m}$

- Diameter of the cross-section (circular columns): $139.7 \mathrm{~mm} \leq D \leq 508 \mathrm{~mm}$

- Major axis dimension (elliptical columns): $150 \mathrm{~mm} \leq 2 a \leq 500 \mathrm{~mm}$ (with aspect ratio $a / b=2)$

- Concrete grades: C20/25 - C40/50

- Percentage of reinforcement: $0 \% \leq \rho \leq 5 \%$

- Standard fire exposure time: $R \leq 120 \mathrm{~min}$

\section{SUMMARY AND CONCLUSIONS}

This paper presented a simple calculation model for evaluating the design axial buckling load in the fire situation of bar-reinforced CFT columns of circular and elliptical cross-section under concentric axial load. It is a continuation of the method developed by the authors in a previous paper [1] for unreinforced circular CFT columns, and completes a full 
method based on the general rules for the fire resistance evaluation of composite columns in Clause 4.3.5.1 of EN 1994-1-2.

Parametric studies were carried out by means of a validated numerical model, and through their results, design equations and tables were proposed for defining the appropriate values of the different parts of the method, as the flexural stiffness reduction coefficients of the different components of the composite section or the suitable buckling curves for different values of the percentage of reinforcement.

It was observed that, as the reinforcement ratio increases, the normalised buckling load decreases, therefore different buckling curves were proposed for increasing reinforcement ratios. Buckling curve "b" was proposed for a $2.5 \%$ reinforcement ratio, while buckling curve "c" was recommended for a 5\% reinforcement ratio.

The previously proposed expressions for the equivalent temperatures and reduction coefficients of the steel tube and concrete core were found to be also valid for bar-reinforced columns, combined with specific equivalent temperatures and reduction coefficients for the reinforcing bars.

Good agreement was obtained between the proposed method predictions and the numerical simulations, improving the accuracy of the currently available methods in Eurocode 4 Part 1.2. The proposed method provided also a good estimation of the buckling resistance of bar-reinforced CFT columns at elevated temperatures as compared with real fire tests and other methods.

Finally, it was confirmed that the proposed method for circular columns can also be applied to elliptical columns producing reasonable results, nevertheless, specific expressions and tables were proposed for CFEHS columns, leading to accurate predictions. 
The proposed calculation method will be extended in the future to square and rectangular sections, as well as to columns subjected to eccentric load, for which further parametric studies will be necessary.

\section{ACKNOWLEDGEMENTS}

The authors would like to express their sincere gratitude to the Spanish "Ministerio de Ciencia e Innovación" for the help provided through the Project BIA2009-9411 and to the European Union through the FEDER funds.

\section{REFERENCES}

[1] Espinos A, Romero ML, Hospitaler A. Simple calculation model for evaluating the fire resistance of unreinforced concrete filled tubular columns. Engineering Structures 2012; 42:231-244.

[2] Zhao XL, Han LH, Lu H. Concrete-filled tubular members and connections. Spon Press; 2010.

[3] Han LH, Zhao XL, Yang YF, Feng JB. Experimental study and calculation of the fire resistance of concrete-filled hollow steel columns. Journal of Structural Engineering, ASCE 2003; 129(3):346-356.

[4] Han LH, Yang YF, Xu L. An experimental study and calculation on the fire resistance of concrete-filled SHS columns. Journal of Constructional Steel Research 2003; 59(4):427452.

[5] Kodur VKR. Performance-based fire resistance design of concrete-filled steel columns. Journal of Constructional Steel Research 1999; 51:21-36.

[6] Kodur VKR. Guidelines for fire resistant design of concrete-filled steel HSS columns State-of-the-art and research needs. Steel Structures 2007; 7:173-182. 
[7] Kodur VKR, MacKinnon DH. Design of concrete-filled hollow structural steel columns for fire endurance. Engineering Journal-AISC 2000; 37(1):13-24.

[8] Park S, Choi S, Chung K. A study on the fire-resistance of concrete-filled steel square tube columns without fire protection under constant central axial loads. Steel and Composite Structures 2008; 8(6):491-510.

[9] Park S, Chung K, Choi S. A study on failure prediction and design equation of concrete filled square steel tube columns under fire condition. Steel Structures 2007; 7(3):183191.

[10] CEN. EN 1994-1-2, Eurocode 4: Design of composite steel and concrete structures. Part 1-2: General rules - Structural fire design. Brussels, Belgium: Comité Européen de Normalisation; 2005.

[11] Wang YC, Orton AH. Fire resistant design of concrete filled tubular steel columns. The Structural Engineer 2008; 7:40-45.

[12] Aribert JM, Renaud C, Zhao B. Simplified fire design for composite hollow-section columns. Structures \& Buildings 2008; 161:325-336.

[13] Leskela MV. Inconsistencies in the fire design rules of composite columns to EN 1994-12. Steel Concrete Composite and Hybrid Structures, pp. 489-494. Leeds, England; 2009.

[14] Renaud C, Joyeux D, Kruppa J. Improvement and extension of the simple calculation method for fire resistance of unprotected concrete filled hollow columns. CIDECT Research Project 15Q-12/03. Saint-Rémy-lès-Chevreuse, France: Centre Technique Industriel de la Construction Métallique (CTICM); 2004.

[15] AFNOR. Calcul simplifié de la résistance au feu des profils creux remplis de béton exposés aux conditions d'incendie normalisé. Annexe PCRB, pp. 9-16, NF-EN 1994-12/NA. Paris, France: Association Française de Normalisation; 2007. 
[16] Espinos A. Numerical analysis of the fire resistance of circular and elliptical slender concrete filled tubular columns. Doctoral thesis. Valencia, Spain: Universitat Politècnica de València; 2012. http://hdl.handle.net/10251/17579

[17] Espinos A, Romero ML, Hospitaler A. Advanced model for predicting the fire response of concrete filled tubular columns. Journal of Constructional Steel Research 2010; 66:1030-1046.

[18] Chan TM, Gardner L, Law KH. Structural design of elliptical hollow sections: a review. Structures and Buildings 2010; 163(6):391-402.

[19] Yang H, Lam D, Gardner L. Testing and analysis of concrete-filled elliptical hollow sections. Engineering Structures 2008; 30:3771-3781.

[20] Zhao XL, Packer JA. Tests and design of concrete-filled elliptical hollow section stub columns. Thin-Walled Structures 2009; 47:617-628.

[21] Lam D, Gardner L, Burdett M. Behaviour of axially loaded concrete filled stainless steel elliptical stub columns. Advances in Structural Engineering 2010; 13(3):493-500.

[22] Dai X, Lam D. Numerical modelling of the axial compressive behaviour of short concrete-filled elliptical steel columns. Journal of Constructional Steel Research 2010; 66:931-942.

[23] Scullion T, Ali F, Nadjai A. Experimental study on performance of elliptical section steel columns, under hydrocarbon fire. Journal of Constructional Steel Research 2011; 67(6):986-991.

[24] Scullion T, Ali F, Nadjai A. Finite element numerical evaluation of elliptical hollow section steel columns in fire. Thin-Walled Structures 2012; 55:22-36.

[25] Espinos A, Gardner L, Romero M, Hospitaler A. Fire behaviour of concrete filled elliptical steel columns. Thin-Walled Structures 2011; 49(2):239-255. 
[26] Dai XH, Lam D. Shape effect on the behaviour of axially loaded concrete filled steel tubular stub columns at elevated temperature. Journal of Constructional Steel Research 2012; 73:117-127.

[27] ABAQUS. ABAQUS/Standard Version 6.10 User's Manual: Volumes I-III. Pawtucket, Rhode Island: Hibbitt, Karlsson \& Sorensen, Inc.; 2010.

[28] Romero ML, Moliner V, Espinos A, Ibañez C, Hospitaler A. Fire behavior of axially loaded slender high strength concrete-filled tubular columns. Journal of Constructional Steel Research 2011; 67(12):1953-1965.

[29] CEN. EN 1994-1-1, Eurocode 4: Design of composite steel and concrete structures. Part 1-1: General rules and rules for buildings. Brussels, Belgium: Comité Européen de Normalisation; 2004.

[30] Espinos A, Romero ML, Hospitaler A. Research Report. Development of a simple calculation model for evaluating the fire resistance of concrete filled tubular columns. Valencia, Spain: Universitat Politècnica de València; 2013. http://cfst.blogs.upv.es/files/2013/05/Simple-calculation-model.pdf

[31] Lennon T, Moore DB, Wang YC, Bailey CG. Designers’ guide to EN 1991-1-2, EN 1992-1-2, EN 1993-1-2 and EN 1994-1-2. Thomas Telford Limited; 2007.

[32] Chabot M, Lie TT. Experimental studies on the fire resistance of hollow steel columns filled with bar-reinforced concrete. Internal report No. 628. Ottawa, Canada: Institute for Research in Construction, National Research Council of Canada (NRCC); 1992.

[33] Corus. Celsius 355 Ovals - Sizes and Capacities, EC3 Version. Corus Tubes - Structural \& conveyance business; 2007. 
Espinos A, Romero ML, Hospitaler A. Fire design method for bar-reinforced circular and elliptical concrete filled tubular columns. Eng Struct. 2013;56:384-95. doi: 10.1016/j.engstruct.2013.05.026

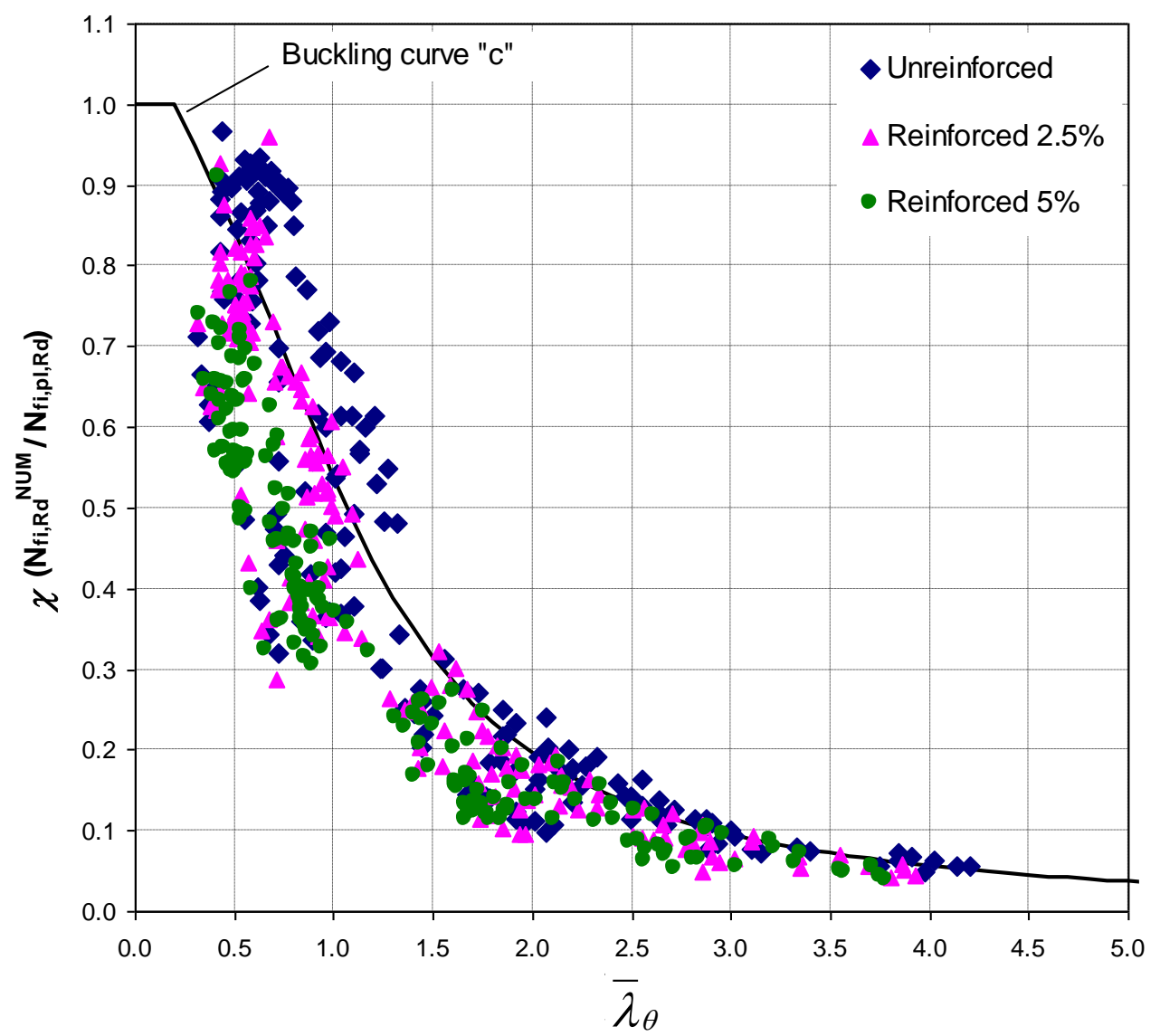

Fig. 1. Evolution of the buckling coefficient with the relative slenderness at elevated temperature, for different reinforcement ratios. 

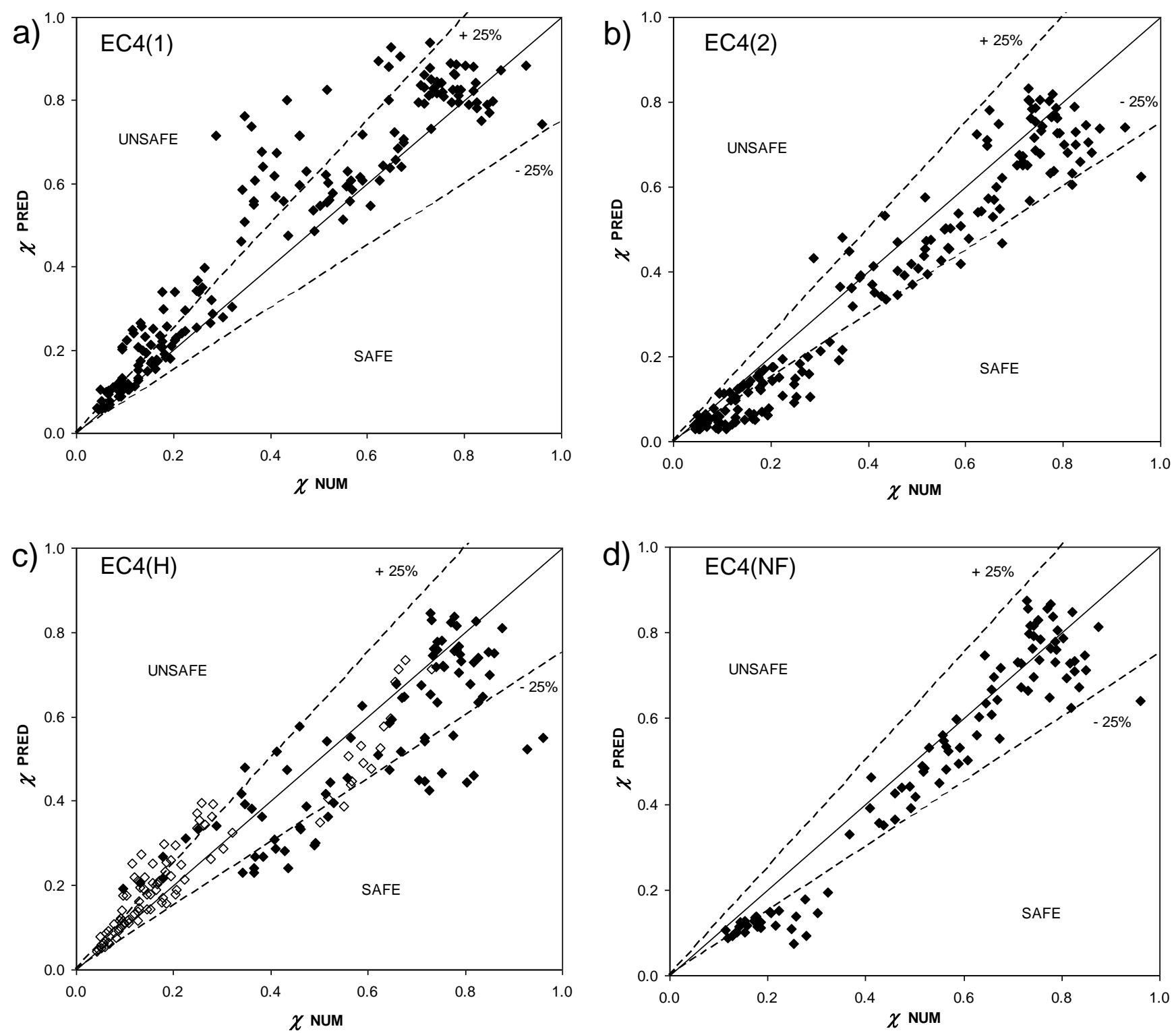

Fig. 2. Comparison between the different approaches studied in terms of the normalised buckling resistance: a) EC4(1), b) EC4(2), c) EC4(H), d) EC4(NF), for a 2.5\% reinforcement ratio. 
a)

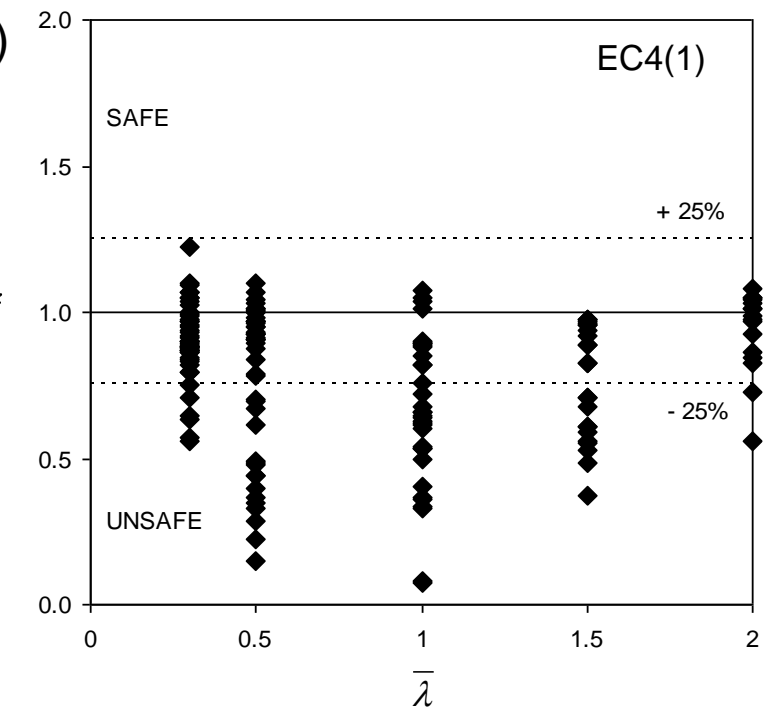

c)

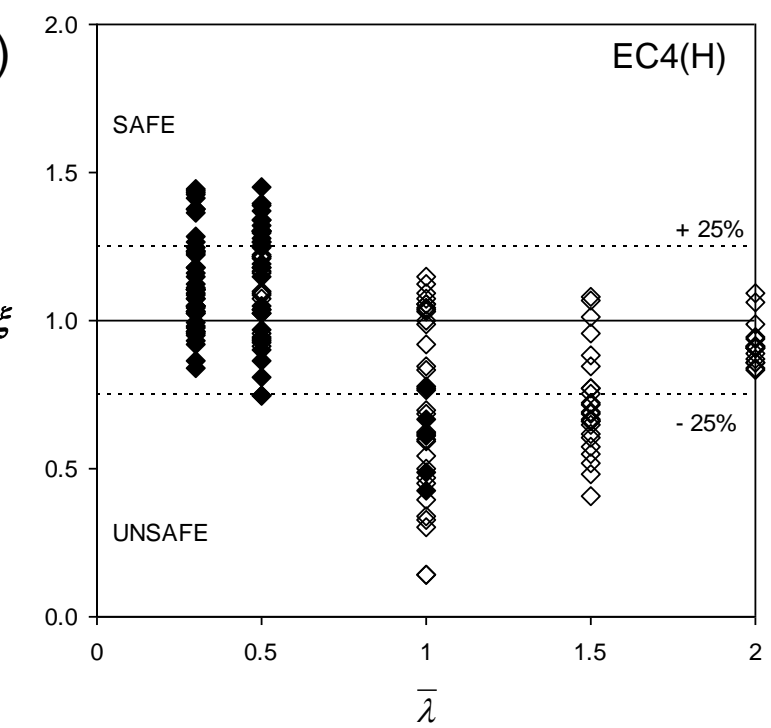

b)

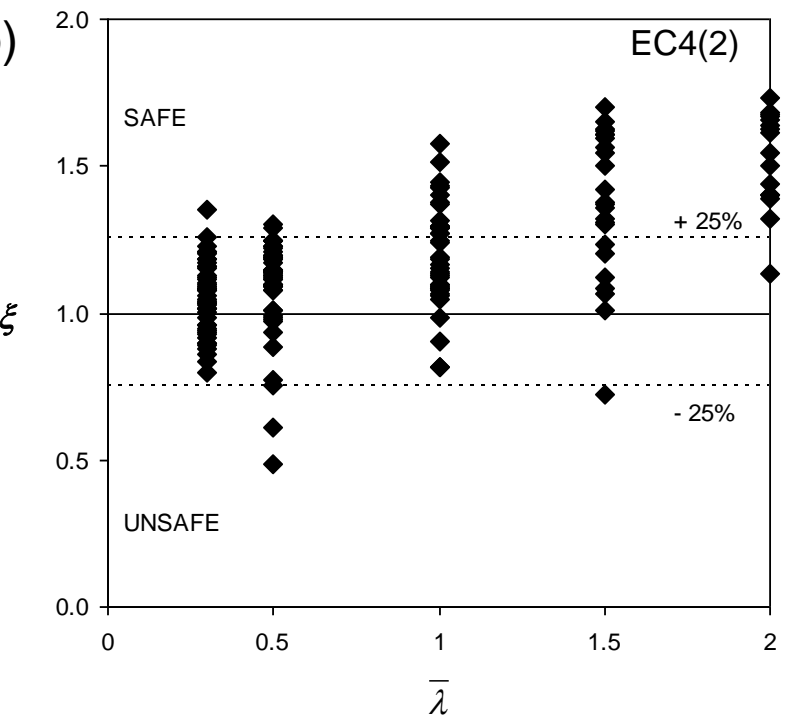

d)

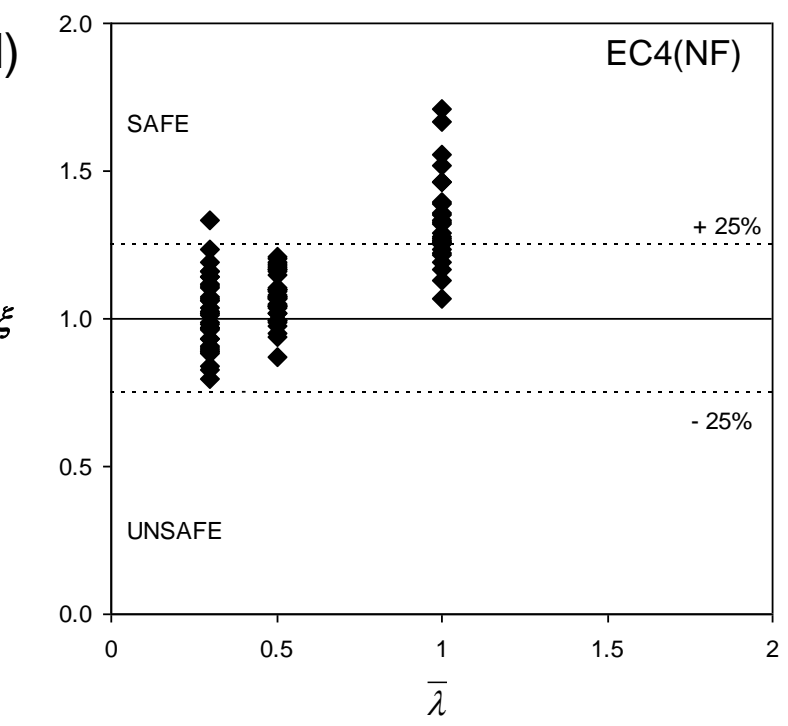

Fig. 3. Evolution of the prediction errors with the relative slenderness of the columns, for the different approaches studied: a) EC4(1), b) EC4(2), c) EC4(H), d) EC4(NF), for a 2.5\% reinforcement ratio. 
Espinos A, Romero ML, Hospitaler A. Fire design method for bar-reinforced circular and elliptical concrete filled tubular columns. Eng Struct. 2013;56:384-95. doi: 10.1016/j.engstruct.2013.05.026

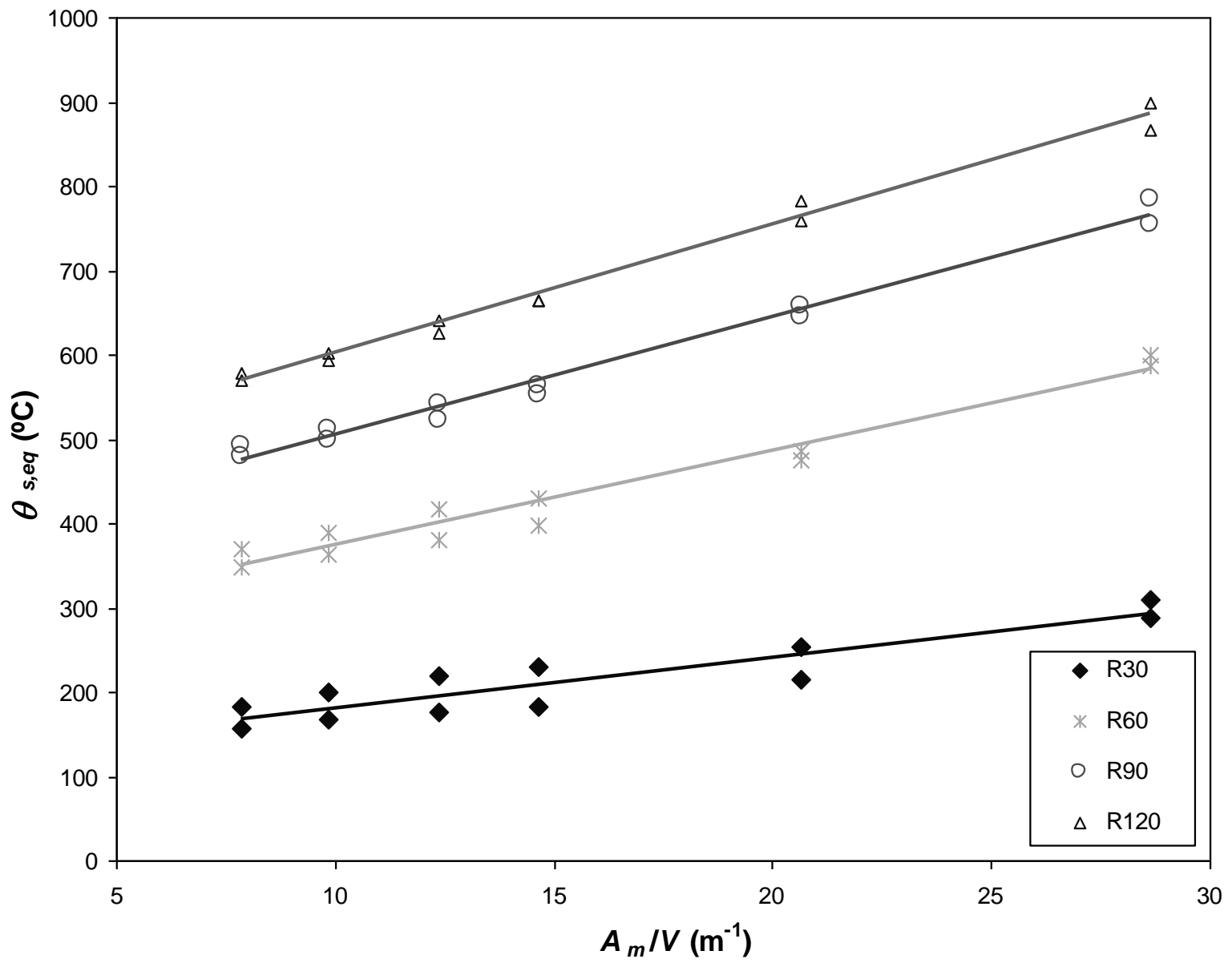

Fig. 4. Evolution of the equivalent temperature of the reinforcing bars with the section factor, for CFCHS columns. 


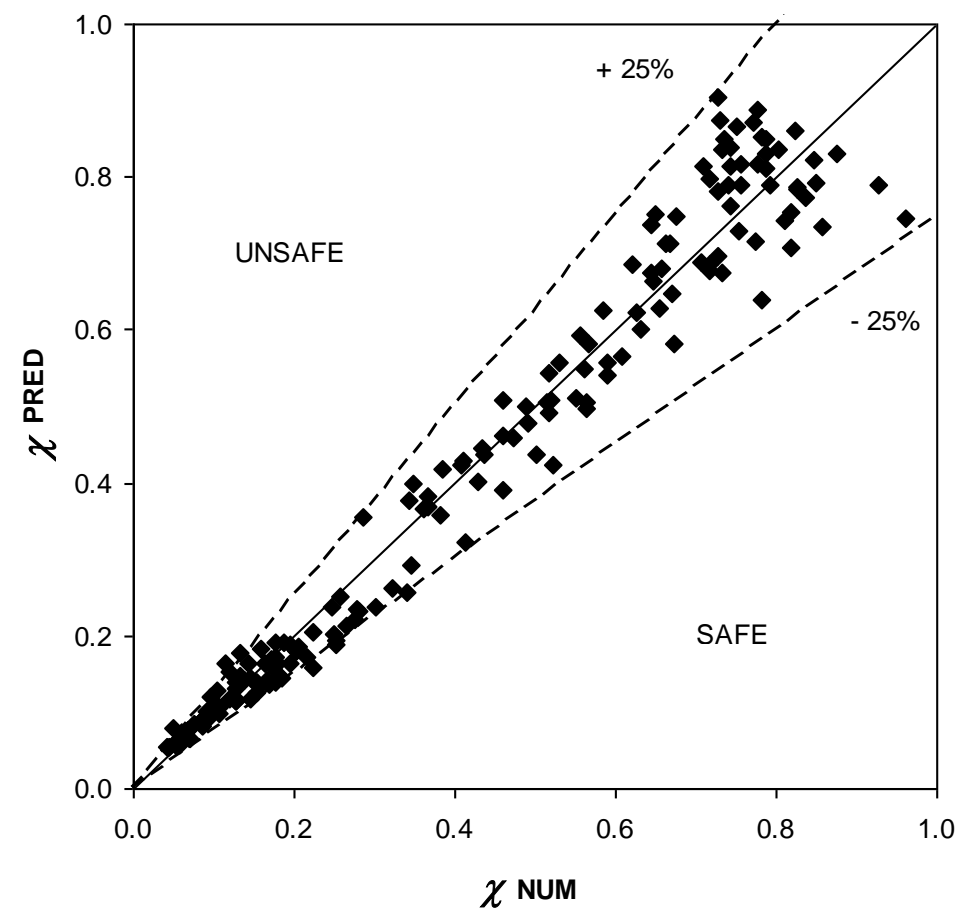

Fig. 5. Comparison between the predictions and numerical simulations in terms of normalised buckling load. Tabulated data, $2.5 \%$ reinforcement ratio. 
Espinos A, Romero ML, Hospitaler A. Fire design method for bar-reinforced circular and elliptical concrete filled tubular columns. Eng Struct. 2013;56:384-95. doi: 10.1016/j.engstruct.2013.05.026

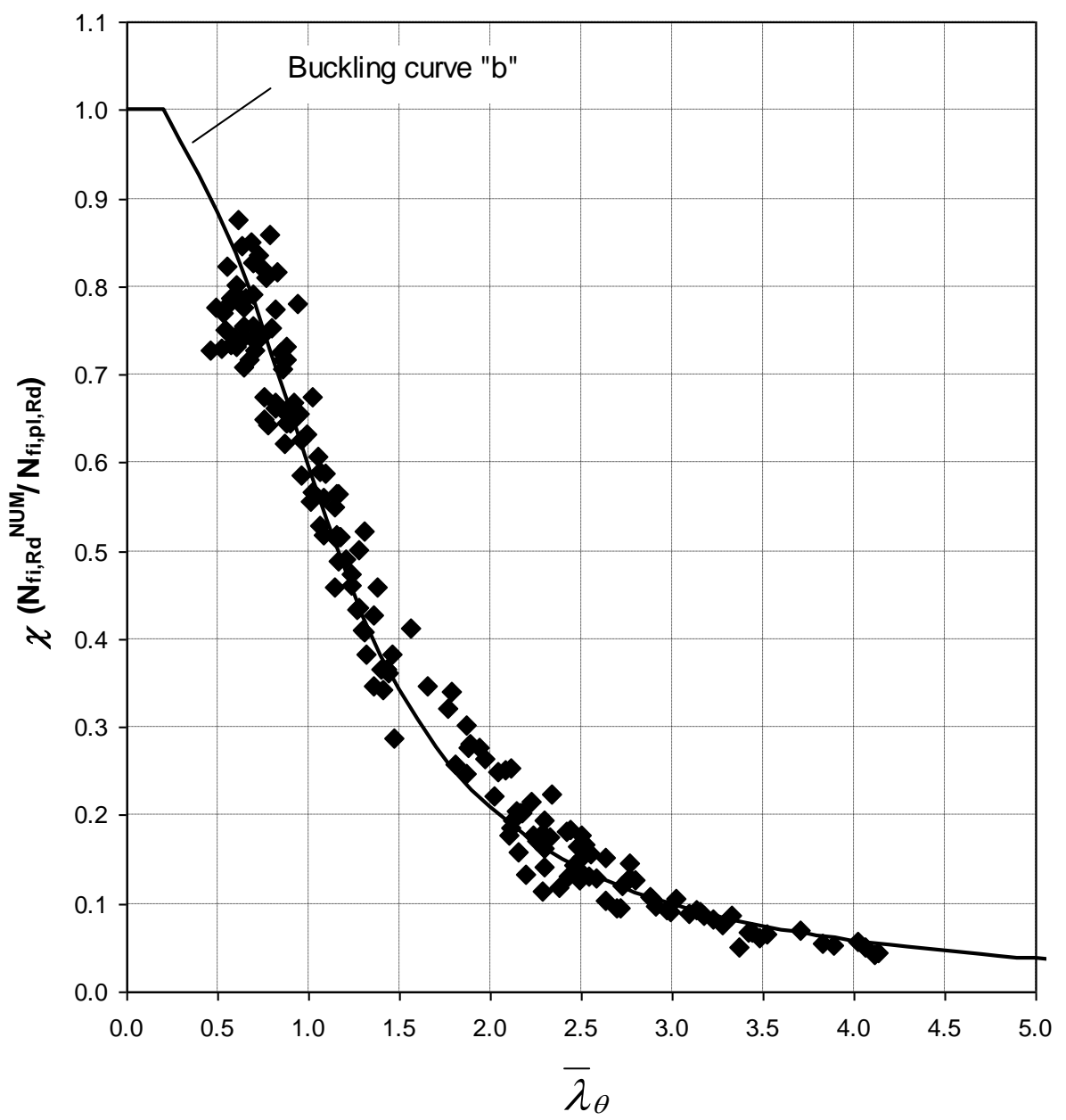

Fig. 6. Evolution of the buckling coefficient with the relative slenderness at elevated temperature. Tabulated data, $2.5 \%$ reinforcement ratio. 
Espinos A, Romero ML, Hospitaler A. Fire design method for bar-reinforced circular and elliptical concrete filled tubular columns. Eng Struct. 2013;56:384-95. doi: 10.1016/j.engstruct.2013.05.026

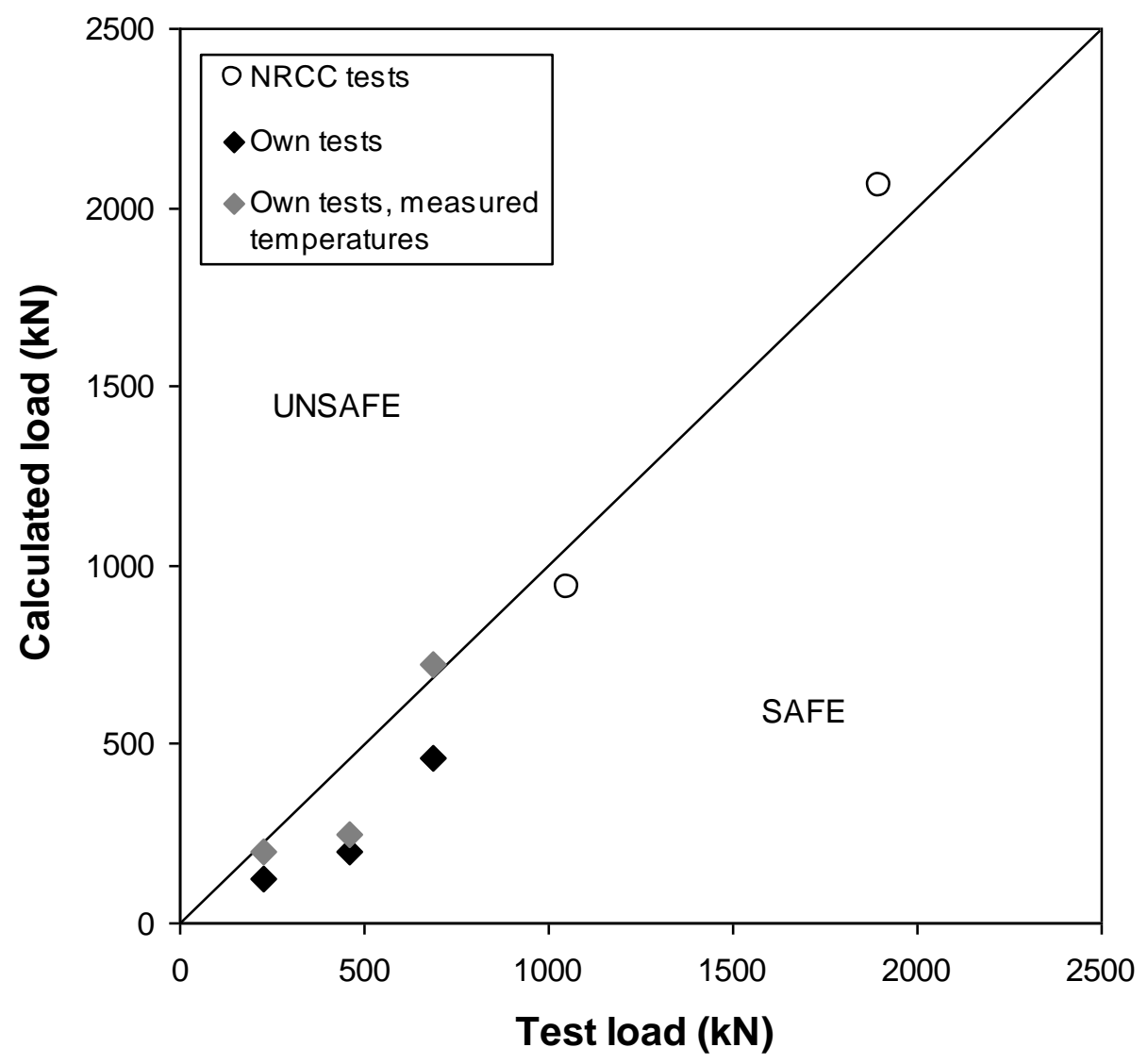

Fig. 7. Comparison of ultimate loads between the proposed method for bar-reinforced columns and tests. 
Espinos A, Romero ML, Hospitaler A. Fire design method for bar-reinforced circular and elliptical concrete filled tubular columns. Eng Struct. 2013;56:384-95. doi: 10.1016/j.engstruct.2013.05.026

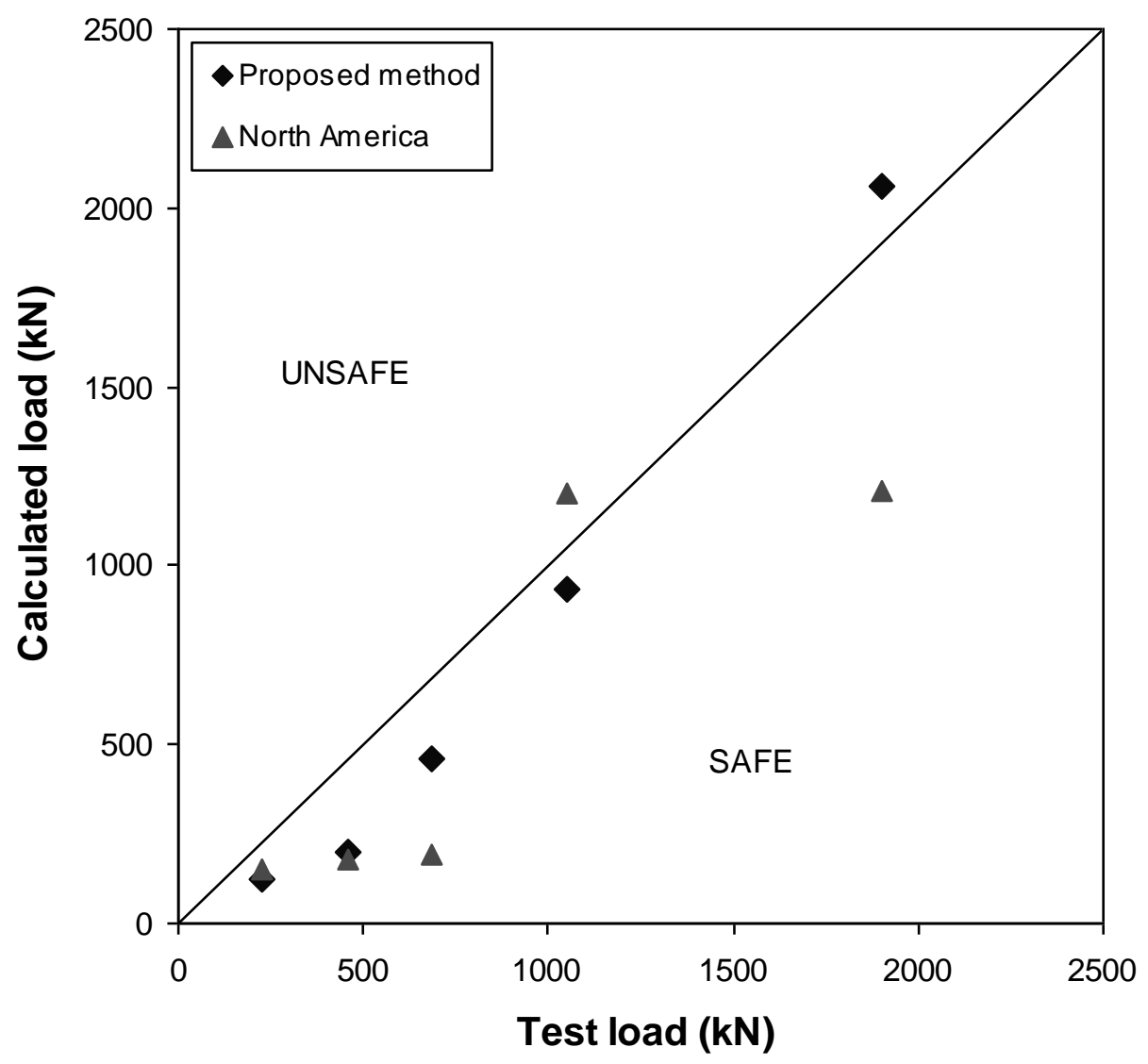

Fig. 8. Comparison of ultimate loads between the proposed method for bar-reinforced columns, Kodur formula and tests. 


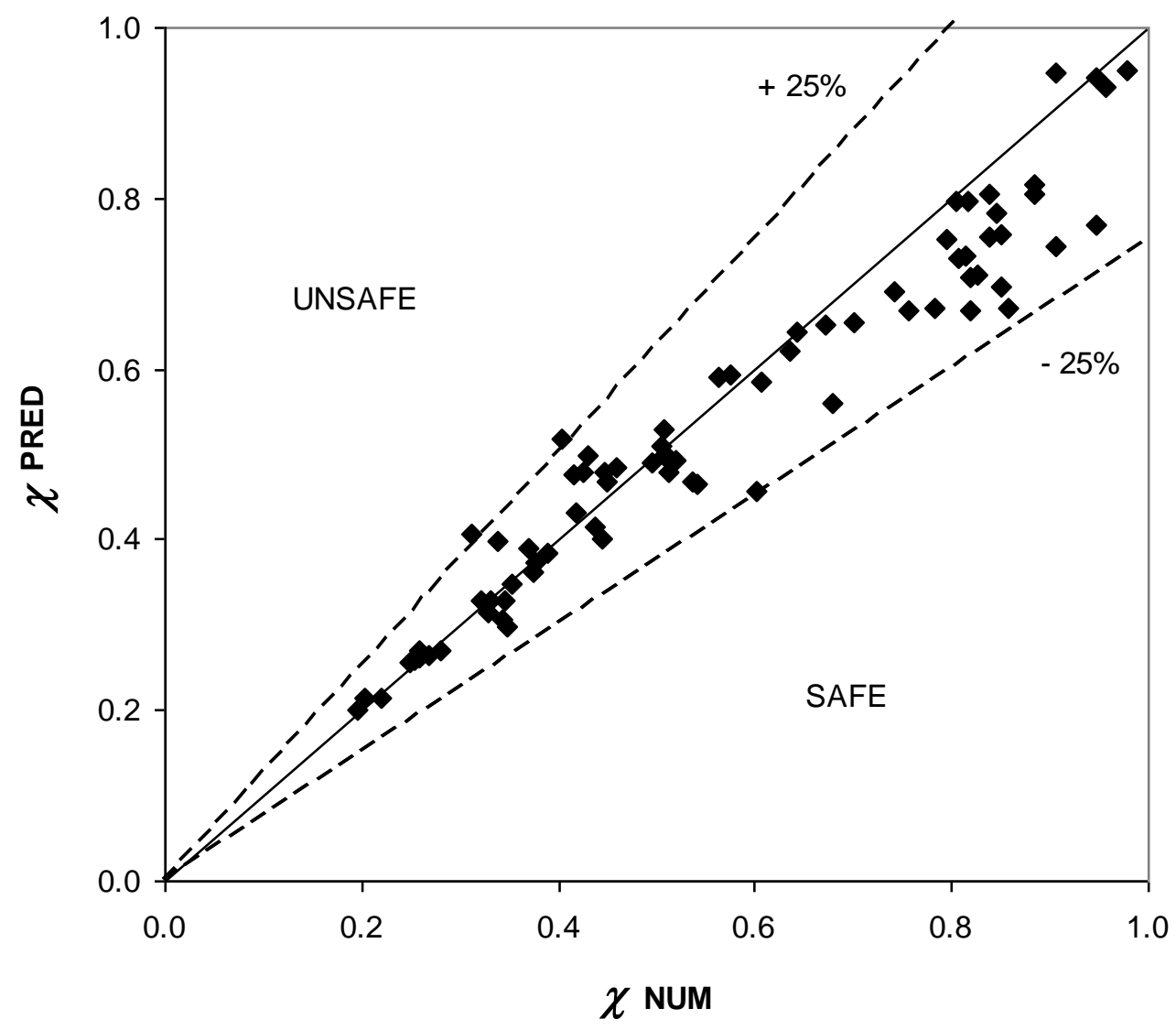

Fig. 9. Comparison between the predictions and numerical simulations for CFEHS columns, in terms of normalised buckling load. 
Espinos A, Romero ML, Hospitaler A. Fire design method for bar-reinforced circular and elliptical concrete filled tubular columns. Eng Struct. 2013;56:384-95. doi: 10.1016/j.engstruct.2013.05.026

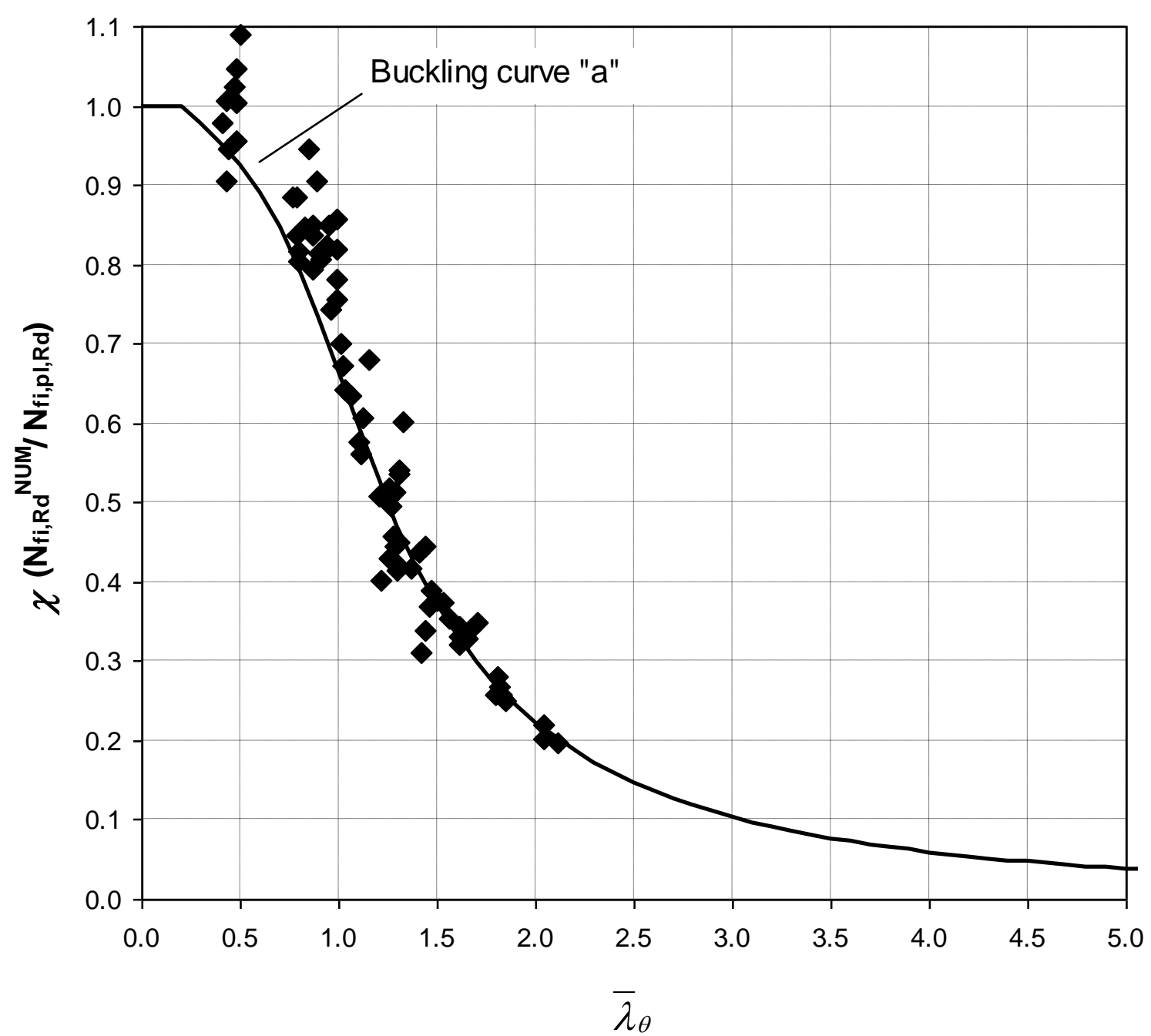

Fig. 10. Evolution of the buckling coefficient with the relative slenderness at elevated temperature, for CFEHS columns. 
Espinos A, Romero ML, Hospitaler A. Fire design method for bar-reinforced circular and elliptical concrete filled tubular columns. Eng Struct. 2013;56:384-95. doi: 10.1016/j.engstruct.2013.05.026

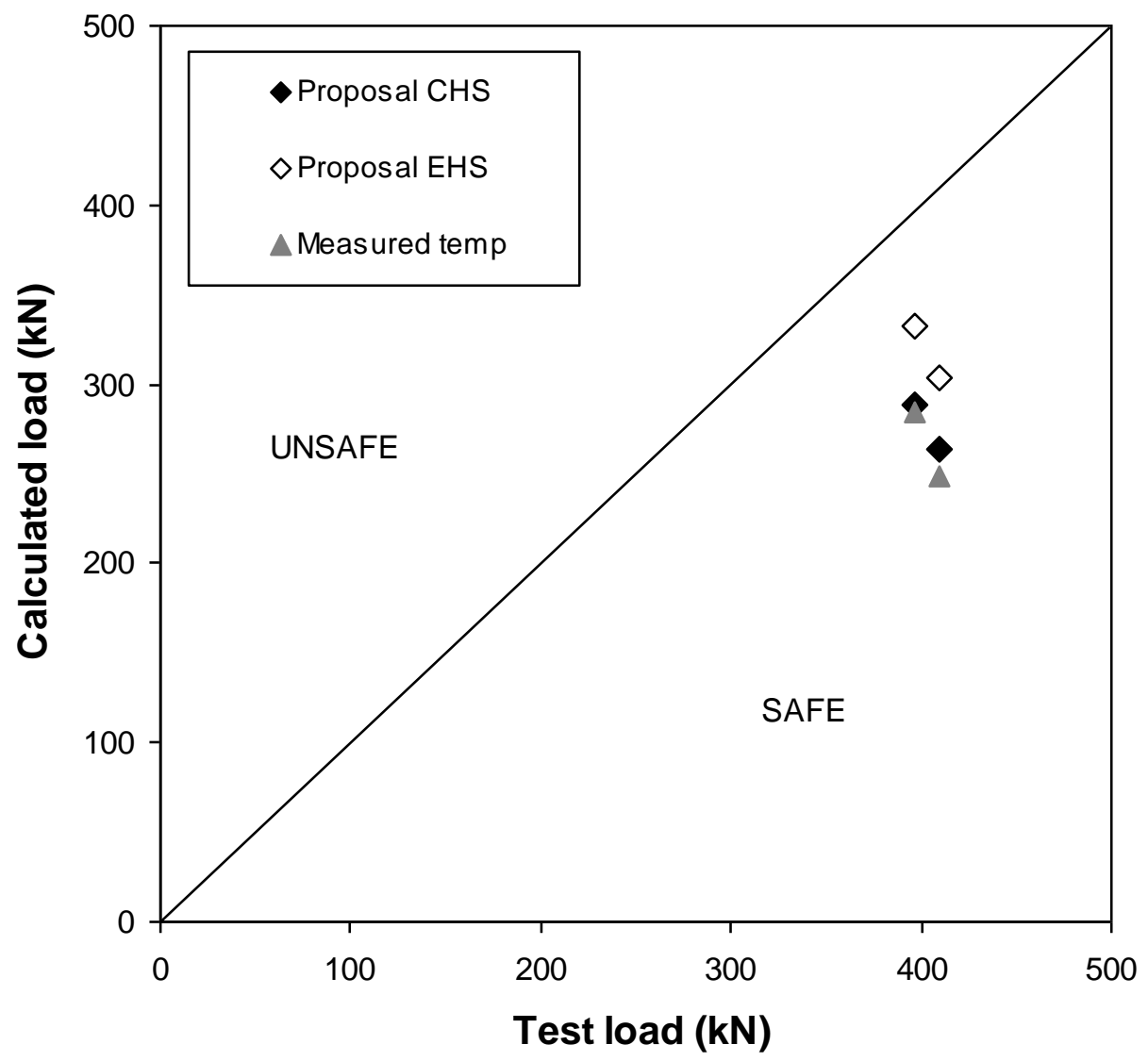

Fig. 11. Comparison of ultimate loads between the proposed method and tests, for CFEHS columns. 
Table 1. Values of the equivalent temperatures for concrete $\left(\theta_{c, e q}\right)$ and steel $\left(\theta_{a, e q}\right)$ in function of the section factor, for CFCHS columns

\begin{tabular}{|c|c|c|c|c|c|c|c|c|c|}
\hline & \multicolumn{2}{|c|}{ R30 } & \multicolumn{2}{|c|}{ R60 } & \multicolumn{2}{|c|}{ R90 } & \multicolumn{2}{|c|}{ R120 } \\
\hline & & $\theta_{c, e q}\left({ }^{\circ} \mathrm{C}\right)$ & $\theta_{a, e q}\left({ }^{\circ} \mathrm{C}\right)$ & $\theta_{c, e q}\left({ }^{\circ} \mathrm{C}\right)$ & $\theta_{a, e q}\left({ }^{\circ} \mathrm{C}\right)$ & $\theta_{c, e q}\left({ }^{\circ} \mathrm{C}\right)$ & $\theta_{a, e q}\left({ }^{\circ} \mathrm{C}\right)$ & $\theta_{c, e q}\left({ }^{\circ} \mathrm{C}\right)$ & $\theta_{a, e q}\left({ }^{\circ} \mathrm{C}\right)$ \\
\hline \multirow{6}{*}{$\begin{array}{c}A_{m} / V \\
\left(\mathbf{m}^{-1}\right)\end{array}$} & 5 & 141 & 636 & 197 & 857 & 316 & 957 & 344 & 1013 \\
\hline & 10 & 210 & 652 & 342 & 869 & 422 & 964 & 487 & 1018 \\
\hline & 15 & 278 & 669 & 453 & 880 & 571 & 971 & 659 & 1024 \\
\hline & 20 & 346 & 686 & 549 & 891 & 721 & 978 & 819 & 1030 \\
\hline & 25 & 413 & 703 & 647 & 903 & 831 & 985 & 928 & 1035 \\
\hline & 30 & 480 & 719 & 764 & 914 & 860 & 992 & 947 & 1041 \\
\hline
\end{tabular}


Espinos A, Romero ML, Hospitaler A. Fire design method for bar-reinforced circular and elliptical concrete filled tubular columns. Eng Struct. 2013;56:384-95. doi: 10.1016/j.engstruct.2013.05.026

Table 2. Values of the partial reduction coefficient $\varphi_{a, \theta 1}$ for stocky columns $\left(\ell_{\theta} / D \leq 12\right)$

\begin{tabular}{cc}
\hline$D / t$ & $\varphi_{a, \theta 1}$ \\
\hline$<15$ & 0.75 \\
$15-35$ & 1 \\
$35-45$ & 1.25 \\
$>45$ & 2.5 \\
\hline
\end{tabular}


Espinos A, Romero ML, Hospitaler A. Fire design method for bar-reinforced circular and elliptical concrete filled tubular columns. Eng Struct. 2013;56:384-95. doi: 10.1016/j.engstruct.2013.05.026

Table 3. Values of the reduction coefficient of steel $\left(\varphi_{a, \theta}\right)$, for CFCHS columns

\begin{tabular}{|c|c|cccc|}
\cline { 3 - 6 } \multicolumn{2}{c|}{} & \multicolumn{4}{c|}{$A_{m} / V\left(\mathbf{m}^{-1}\right)$} \\
\cline { 3 - 6 } \multicolumn{1}{c|}{} & $<\mathbf{1 0}$ & $\mathbf{1 0}-\mathbf{1 5}$ & $\mathbf{1 5}-\mathbf{2 0}$ & $\mathbf{2 0}$ \\
\hline \multirow{4}{*}{$\ell_{\theta} / D$} & $\leq \mathbf{1 2}$ & 0.4 & 0.35 & 0.3 & 0.25 \\
& $\mathbf{2 4}$ & - & 0.5 & 0.5 & 0.4 \\
& $\mathbf{3 6}$ & - & - & 0.7 & 0.7 \\
& $\geq \mathbf{4 6}$ & - & - & - & 1 \\
\hline
\end{tabular}


Table 4. Summary of the analysis cases used in the parametric studies

\begin{tabular}{|c|cc|cc|cc|cc|cc|c|c|}
\hline Variable & \multicolumn{10}{|c|}{ Specified values } \\
\hline$D(\mathrm{~mm})$ & 139.7 & 193.7 & 273 & 323.9 & 406.4 & 508 \\
\hline$t(\mathrm{~mm})$ & 3.2 & 12.5 & 5 & 16 & 5 & 16 & 6.3 & 16 & 8 & 16 & 10 & 16 \\
\hline & 0.3 & 0.3 & 0.3 & 0.3 & 0.3 & 0.3 & 0.3 & 0.3 & 0.3 & 0.3 & 0.3 & 0.3 \\
& 0.5 & 0.5 & 0.5 & 0.5 & 0.5 & 0.5 & 0.5 & 0.5 & 0.5 & 0.5 & 0.5 & 0.5 \\
$\bar{\lambda}$ & 1 & 1 & 1 & 1 & 1 & 1 & 1 & 1 & 1 & 1 & - & - \\
& 1.5 & 1.5 & 1.5 & 1.5 & 1.5 & 1.5 & - & - & - & - & - & - \\
& 2 & 2 & 2 & 2 & - & - & - & - & - & - & - & - \\
\hline$\rho(\%)$ & \multicolumn{11}{|c|}{$2.5 ; 5$} & $50 ; 90 ; 120$ \\
\hline$R(\mathrm{~min})$ & \multicolumn{11}{|c|}{} \\
\hline
\end{tabular}


Espinos A, Romero ML, Hospitaler A. Fire design method for bar-reinforced circular and elliptical concrete filled tubular columns. Eng Struct. 2013;56:384-95. doi: 10.1016/j.engstruct.2013.05.026

Table 5. Values of the equivalent temperatures for the reinforcing bars $\left(\theta_{s, e q}\right)$ in function of the section factor, for CFCHS columns

\begin{tabular}{|c|c|cccc|}
\cline { 3 - 6 } \multicolumn{2}{c|}{} & \multicolumn{4}{c|}{$\boldsymbol{\theta}_{s, e q}\left({ }^{\mathbf{}} \mathbf{C}\right)$} \\
\cline { 3 - 6 } \multicolumn{2}{c|}{} & $\mathbf{R 3 0}$ & $\mathbf{R 6 0}$ & $\mathbf{R 9 0}$ & $\mathbf{R 1 2 0}$ \\
\hline & $\mathbf{5}$ & 152 & 318 & 435 & 525 \\
& $\mathbf{1 0}$ & 181 & 374 & 505 & 601 \\
$\boldsymbol{A}_{\boldsymbol{m}} / \boldsymbol{V}$ & $\mathbf{1 5}$ & 211 & 430 & 575 & 677 \\
$\left(\mathbf{m}^{-1}\right)$ & $\mathbf{2 0}$ & 241 & 485 & 644 & 754 \\
& $\mathbf{2 5}$ & 271 & 541 & 714 & 830 \\
& $\mathbf{3 0}$ & 301 & 597 & 784 & 906 \\
\hline
\end{tabular}


Espinos A, Romero ML, Hospitaler A. Fire design method for bar-reinforced circular and elliptical concrete filled tubular columns. Eng Struct. 2013;56:384-95. doi: 10.1016/j.engstruct.2013.05.026

Table 6. Summary of the errors in the prediction of the design axial buckling load in the fire situation, for CFCHS columns

\begin{tabular}{ccccccc}
\cline { 2 - 7 } & \multicolumn{2}{c}{$\boldsymbol{\rho}=\mathbf{0 \%}$} & \multicolumn{2}{c}{$\boldsymbol{\rho}=\mathbf{2 . 5 \%}$} & \multicolumn{2}{c}{$\boldsymbol{\rho}=\mathbf{5 \%}$} \\
\cline { 2 - 7 } & Mean & Std. dev. & Mean & Std. dev. & Mean & Std. dev. \\
\hline Design equation (Eq. 4) & 1.09 & 0.11 & 1.04 & 0.14 & 1.05 & 0.18 \\
Tabulated data (Table 3) & 1.04 & 0.11 & 1.00 & 0.14 & 1.00 & 0.18 \\
\hline
\end{tabular}


Espinos A, Romero ML, Hospitaler A. Fire design method for bar-reinforced circular and elliptical concrete filled tubular columns. Eng Struct. 2013;56:384-95. doi: 10.1016/j.engstruct.2013.05.026

Table 7. Summary of the proposed buckling curve and reduction coefficient of the reinforcing bars

\begin{tabular}{cccc}
\hline Reinforcement ratio & $\boldsymbol{\rho}=\mathbf{0 \%}$ & $\mathbf{0 \%}<\rho \leq \mathbf{2 . 5 \%}$ & $\mathbf{2 . 5 \%}<\boldsymbol{\rho 5} \mathbf{5 \%}$ \\
\hline Buckling curve & "a" $(\alpha=0.21)$ & "b" $(\alpha=0.34)$ & "c" $(\alpha=0.49)$ \\
$\varphi_{s, \theta}$ & - & 0.6 & 0.3 \\
\hline
\end{tabular}


Table 8. Values of the equivalent temperatures for concrete $\left(\theta_{c, e q}\right)$ and steel $\left(\theta_{a, e q}\right)$ in function of the section factor, for CFEHS columns

\begin{tabular}{|c|c|c|c|c|c|c|c|c|c|}
\hline & \multicolumn{2}{|c|}{ R30 } & \multicolumn{2}{|c|}{ R60 } & \multicolumn{2}{|c|}{ R90 } & \multicolumn{2}{|c|}{ R120 } \\
\hline & & $\theta_{c, e q}\left({ }^{\circ} \mathrm{C}\right)$ & $\theta_{a, e q}\left({ }^{\circ} \mathrm{C}\right)$ & $\theta_{c, e q}\left({ }^{\circ} \mathrm{C}\right)$ & $\theta_{a, e q}\left({ }^{\circ} \mathrm{C}\right)$ & $\theta_{c, e q}\left({ }^{\circ} \mathrm{C}\right)$ & $\theta_{a, e q}\left({ }^{\circ} \mathrm{C}\right)$ & $\theta_{c, e q}\left({ }^{\circ} \mathrm{C}\right)$ & $\theta_{a, e q}\left({ }^{\circ} \mathrm{C}\right)$ \\
\hline \multirow{9}{*}{$\begin{array}{c}A_{m} / V \\
\left(\mathbf{m}^{-1}\right)\end{array}$} & 5 & 232 & 623 & 359 & 855 & 410 & 956 & 465 & 1014 \\
\hline & 10 & 299 & 641 & 475 & 866 & 593 & 963 & 696 & 1019 \\
\hline & 15 & 361 & 659 & 577 & 878 & 727 & 970 & 842 & 1024 \\
\hline & 20 & 419 & 677 & 663 & 889 & 822 & 976 & 925 & 1029 \\
\hline & 25 & 472 & 695 & 734 & 900 & 884 & 983 & 965 & 1034 \\
\hline & 30 & 520 & 713 & 789 & 912 & 922 & 990 & 985 & 1040 \\
\hline & 35 & 564 & 731 & 828 & 923 & 945 & 997 & 1005 & 1045 \\
\hline & 40 & 603 & 749 & 853 & 934 & 961 & 1004 & 1046 & 1050 \\
\hline & 45 & 232 & 623 & 359 & 855 & 410 & 956 & 465 & 1014 \\
\hline
\end{tabular}


Espinos A, Romero ML, Hospitaler A. Fire design method for bar-reinforced circular and elliptical concrete filled tubular columns. Eng Struct. 2013;56:384-95. doi: 10.1016/j.engstruct.2013.05.026

Table 9. Values of the equivalent temperatures for the reinforcing bars $\left(\theta_{s, e q}\right)$ in function of the section factor, for CFEHS columns

\begin{tabular}{|c|c|cccc|}
\cline { 3 - 6 } \multicolumn{2}{c|}{} & \multicolumn{4}{c|}{$\boldsymbol{\theta}_{s, \boldsymbol{e q}}\left({ }^{\mathbf{0}} \mathbf{C}\right)$} \\
\cline { 3 - 6 } \multicolumn{2}{c|}{} & $\mathbf{R 3 0}$ & $\mathbf{R 6 0}$ & $\mathbf{R 9 0}$ & $\mathbf{R 1 2 0}$ \\
\hline & $\mathbf{5}$ & 176 & 355 & 422 & 510 \\
& $\mathbf{1 0}$ & 182 & 371 & 521 & 629 \\
& $\mathbf{1 5}$ & 201 & 427 & 611 & 731 \\
& $\mathbf{2 0}$ & 233 & 506 & 692 & 816 \\
$\boldsymbol{A}_{\boldsymbol{m}} / \boldsymbol{V}$ & $\mathbf{2 5}$ & 277 & 593 & 763 & 884 \\
$\left(\mathbf{m}^{-\mathbf{1}}\right)$ & $\mathbf{3 0}$ & 333 & 671 & 825 & 935 \\
& $\mathbf{3 5}$ & 402 & 724 & 878 & 969 \\
& $\mathbf{4 0}$ & 483 & 736 & 922 & 986 \\
& $\mathbf{4 5}$ & 176 & 355 & 422 & 510 \\
\hline
\end{tabular}


Espinos A, Romero ML, Hospitaler A. Fire design method for bar-reinforced circular and elliptical concrete filled tubular columns. Eng Struct. 2013;56:384-95. doi: 10.1016/j.engstruct.2013.05.026

Table 10. Summary of the errors in the prediction of the design axial buckling load in the fire situation, for CFEHS columns

\begin{tabular}{cccccccc}
\cline { 2 - 7 } & \multicolumn{2}{c}{$\begin{array}{c}\text { Option 1 } \\
(\boldsymbol{D}=\mathbf{2 a})\end{array}$} & \multicolumn{2}{c}{$\begin{array}{c}\text { Option 2 } \\
(\boldsymbol{D}=\mathbf{2 b})\end{array}$} & \multicolumn{2}{c}{$\begin{array}{c}\text { Option 3 } \\
(\boldsymbol{D}=\boldsymbol{P} / \boldsymbol{\pi})\end{array}$} \\
\cline { 2 - 8 } & Mean & Std. dev. & Mean & Std. dev. & Mean & Std. dev. \\
\hline Design equation (Eq. 4) & 1.20 & 0.14 & 1.01 & 0.14 & 1.14 & 0.13 \\
Tabulated data (Table 3) & 1.02 & 0.19 & 0.95 & 0.13 & 1.01 & 0.17 \\
\hline
\end{tabular}


Espinos A, Romero ML, Hospitaler A. Fire design method for bar-reinforced circular and elliptical concrete filled tubular columns. Eng Struct. 2013;56:384-95. doi: 10.1016/j.engstruct.2013.05.026

Table 11. Values of the reduction coefficient of steel $\left(\varphi_{a, \theta}\right)$, for CFEHS columns

\begin{tabular}{|c|c|ccccc|}
\cline { 3 - 8 } \multicolumn{2}{c|}{} & \multicolumn{6}{c|}{$\boldsymbol{A}_{m} / \boldsymbol{V}\left(\mathbf{m}^{-1}\right)$} \\
\cline { 3 - 8 }$\ell_{\theta} / D$ & $<\mathbf{1 0}$ & $\mathbf{1 0}-\mathbf{1 5}$ & $\mathbf{1 5}-\mathbf{2 0}$ & $\mathbf{2 0}-\mathbf{4 0}$ & $\geq \mathbf{4 0}$ \\
\hline & $\leq \mathbf{1 2}$ & 0.4 & 0.35 & 0.3 & 0.25 & 0.2 \\
& $\mathbf{2 4}$ & - & 0.5 & 0.5 & 0.4 & 0.3 \\
& $\mathbf{3 6}$ & - & - & 0.7 & 0.7 & 0.7 \\
& $\geq \mathbf{4 6}$ & - & - & - & 1 & 1 \\
\hline
\end{tabular}


Espinos A, Romero ML, Hospitaler A. Fire design method for bar-reinforced circular and elliptical concrete filled tubular columns. Eng Struct. 2013;56:384-95. doi: 10.1016/j.engstruct.2013.05.026

Table 12. Summary of the errors in the prediction of the design axial buckling load in the fire situation, for CFEHS columns

\begin{tabular}{ccc}
\cline { 2 - 3 } & \multicolumn{2}{c}{$\begin{array}{c}\text { Option 2 } \\
(\boldsymbol{D}=\mathbf{2 b})\end{array}$} \\
\cline { 2 - 3 } & Mean & Std. dev. \\
\hline Equation (4) & 1.01 & 0.14 \\
Table 11 & 1.00 & 0.15 \\
Equation (11) & 1.04 & 0.10 \\
\hline
\end{tabular}


Table 13. Summary of the results in the prediction of the design axial buckling load in the fire situation, for column E220-110-12-3-30-00-20

\begin{tabular}{|c|c|c|c|c|c|c|c|}
\hline & & \multicolumn{2}{|c|}{$\begin{array}{c}\text { Option 1 } \\
\text { (Proposal CFCHS) }\end{array}$} & \multicolumn{2}{|c|}{$\begin{array}{c}\text { Option 2 } \\
\text { (Proposal CFEHS) }\end{array}$} & \multicolumn{2}{|c|}{$\begin{array}{c}\text { Option 3 } \\
\text { (Measured temp.) }\end{array}$} \\
\hline & $\overline{N(\mathrm{kN})}$ & $N_{f i, R d}(\mathbf{k N})$ & $N / N_{f i, R d}$ & $N_{f i, R d}(\mathrm{kN})$ & $N / N_{f i, R d}$ & $N_{f i, R d}(\mathrm{kN})$ & $N / N_{f i, R d}$ \\
\hline & 397. & & 138 & 332.32 & 1.20 & 283.81 & 1.40 \\
\hline Equation (11) & 397.19 & 275.01 & 1.44 & 316.98 & 1.25 & 271.86 & 1.46 \\
\hline
\end{tabular}


Table 14. Overview of the proposed calculation method Equivalent
temperatures

2) Cross-sectional plastic resistance

Effective flexural stiffness

3) Effective length of the column

4) Euler buckling load

\section{5) Relative} slenderness

6) Reduction coefficient

7) Design axial
buckling load

$$
\begin{array}{|lll}
\hline \theta_{a, e q} & \theta_{c, e q} & \theta_{s, e q} \\
\hline
\end{array}
$$

- CFCHS columns: from eq. 1,2 and 7 or alternatively Tables 1 and 5

- CFEHS columns: from eq. 8,9 and 10 or alternatively Tables 8 and 9

$$
N_{f i, p l, R d}=A_{a} f_{y}\left(\theta_{a, e q}\right)+A_{c} f_{c}\left(\theta_{c, e q}\right)+A_{s} f_{s}\left(\theta_{s, e q}\right)
$$

Note: Material properties from Table 3.2 and Table 3.3 in EN 1994-1-2

$$
(E I)_{f i, e f f}=\varphi_{a, \theta} E_{a}\left(\theta_{a, e q}\right) I_{a}+\varphi_{c, \theta} E_{c}\left(\theta_{c, e q}\right) I_{c}+\varphi_{s, \theta} E_{s}\left(\theta_{s, e q}\right) I_{s}
$$

Note: Material properties from Table 3.2 and Table 3.3 in EN 1994-1-2

Values of the reduction coefficients:

- $\varphi_{a, \theta}$ from eq. 4 (CFCHS) and eq. 11 (CFEHS) or alternatively from Table $11^{*}$

- $\varphi_{c, \theta}=0.8$

- $\varphi_{s, \theta}$ from Table 7

${ }^{*}$ These values must be corrected with $\varphi_{a, \theta 1}$ for $\ell_{\theta} / D \leq 12$ (from Table 2).

$$
\ell_{\theta}=0.5 L \text { or } 0.7 L \text { as in Clause 4.3.5.1(10) of EN 1994-1-2 }
$$

$$
N_{f i, c r}=\pi^{2}(E I)_{f i, e f f} / \ell_{\theta}^{2}
$$

$$
\bar{\lambda}_{\theta}=\sqrt{N_{f i, p l, R} / N_{f i, c r}}
$$

$\bar{\lambda}_{\theta} \rightarrow \chi \quad$ from the corresponding buckling curve (Table 7)

$$
N_{f i, R d}=\chi N_{f i, p l, R d}
$$




\section{LIST OF FIGURE CAPTIONS}

Fig. 1. Evolution of the buckling coefficient with the relative slenderness at elevated temperature, for different reinforcement ratios.

Fig. 2. Comparison between the different approaches studied in terms of the normalised buckling resistance: a) EC4(1), b) EC4(2), c) EC4(H), d) EC4(NF), for a 2.5\% reinforcement ratio.

Fig. 3. Evolution of the prediction errors with the relative slenderness of the columns, for the different approaches studied: a) EC4(1), b) EC4(2), c) EC4(H), d) EC4(NF), for a $2.5 \%$ reinforcement ratio.

Fig. 4. Evolution of the equivalent temperature of the reinforcing bars with the section factor, for CFCHS columns.

Fig. 5. Comparison between the predictions and numerical simulations in terms of normalised buckling load. Tabulated data, $2.5 \%$ reinforcement ratio.

Fig. 6. Evolution of the buckling coefficient with the relative slenderness at elevated temperature. Tabulated data, $2.5 \%$ reinforcement ratio.

Fig. 7. Comparison of ultimate loads between the proposed method for bar-reinforced columns and tests.

Fig. 8. Comparison of ultimate loads between the proposed method for bar-reinforced columns, Kodur formula and tests.

Fig. 9. Comparison between the predictions and numerical simulations for CFEHS columns, in terms of normalised buckling load.

Fig. 10. Evolution of the buckling coefficient with the relative slenderness at elevated temperature, for CFEHS columns.

Fig. 11. Comparison of ultimate loads between the proposed method and tests, for CFEHS columns. 


\section{LIST OF TABLE CAPTIONS}

Table 1. Values of the equivalent temperatures for concrete $\left(\theta_{c, e q}\right)$ and steel $\left(\theta_{a, e q}\right)$ in function of the section factor, for CFCHS columns

Table 2. Values of the partial reduction coefficient $\varphi_{a, \theta 1}$ for stocky columns $\left(\ell_{\theta} / D \leq 12\right)$

Table 3. Values of the reduction coefficient of steel $\left(\varphi_{a, \theta}\right)$, for CFCHS columns

Table 4. Summary of the analysis cases used in the parametric studies

Table 5. Values of the equivalent temperatures for the reinforcing bars $\left(\theta_{s, e q}\right)$ in function of the section factor, for CFCHS columns

Table 6. Summary of the errors in the prediction of the design axial buckling load in the fire situation, for CFCHS columns

Table 7. Summary of the proposed buckling curve and reduction coefficient of the reinforcing bars

Table 8. Values of the equivalent temperatures for concrete $\left(\theta_{c, e q}\right)$ and steel $\left(\theta_{a, e q}\right)$ in function of the section factor, for CFEHS columns

Table 9. Values of the equivalent temperatures for the reinforcing bars $\left(\theta_{s, e q}\right)$ in function of the section factor, for CFEHS columns

Table 10. Summary of the errors in the prediction of the design axial buckling load in the fire situation, for CFEHS columns

Table 11. Values of the reduction coefficient of steel $\left(\varphi_{a, \theta}\right)$, for CFEHS columns

Table 12. Summary of the errors in the prediction of the design axial buckling load in the fire situation, for CFEHS columns

Table 13. Summary of the results in the prediction of the design axial buckling load in the fire situation, for column E220-110-12-3-30-00-20

Table 14. Overview of the proposed calculation method 